Cochrane Database of Systematic Reviews

\title{
Human chorionic gonadotrophin priming for fertility treatment with in vitro maturation (Review)
}

\author{
Reavey J, Vincent K, Child T, Granne IE
}

Reavey J, Vincent K, Child T, Granne IE.

Human chorionic gonadotrophin priming for fertility treatment with in vitro maturation.

Cochrane Database of Systematic Reviews 2016, Issue 11. Art. No.: CD008720.

DOI: 10.1002/14651858.CD008720.pub2.

www.cochranelibrary.com 
TABLE OF CONTENTS

HEADER

ABSTRACT

PLAIN LANGUAGE SUMMARY

SUMMARY OF FINDINGS

BACKGROUND

OBJECTIVES

METHODS

Figure 1.

Figure 2.

RESULTS

Figure 3.

Figure 4.

Figure 5.

Figure 6.

DISCUSSION

AUTHORS' CONCLUSIONS

ACKNOWLEDGEMENTS

REFERENCES

CHARACTERISTICS OF STUDIES

DATA AND ANALYSES

Analysis 1.1. Comparison 110,000 units hCG priming versus no priming, Outcome 1 Live birth rate.

Analysis 1.2. Comparison 1 10,000 units hCG priming versus no priming, Outcome 2 Miscarriage rate.

Analysis 1.3. Comparison 110,000 units hCG priming versus no priming, Outcome 3 Clinical pregnancy rate.

Analysis 1.4. Comparison 1 10,000 units hCG priming versus no priming, Outcome 4 Number of oocytes retrieved. ADDITIONAL TABLES

APPENDICES

HISTORY

CONTRIBUTIONS OF AUTHORS

DECLARATIONS OF INTEREST

SOURCES OF SUPPORT

DIFFERENCES BETWEEN PROTOCOL AND REVIEW

INDEX TERMS 
[Intervention Review]

\section{Human chorionic gonadotrophin priming for fertility treatment with in vitro maturation}

Jane Reavey ${ }^{1}$, Katy Vincent ${ }^{2}$, Timothy Child ${ }^{2}$, Ingrid E Granne ${ }^{2}$

1Department of Obstetrics and Gynaecology, John Radcliffe Hospital, Oxford, UK. 2Nuffield Department of Obstetrics \& Gynaecology, John Radcliffe Hospital, Oxford, UK

Contact address: Ingrid E Granne, Nuffield Department of Obstetrics \& Gynaecology, John Radcliffe Hospital, Headley Way, Oxford, OX39DU, UK. Ingrid.Granne@obs-gyn.ox.ac.uk.

Editorial group: Cochrane Gynaecology and Fertility Group.

Publication status and date: New, published in Issue 11, 2016.

Citation: Reavey J, Vincent K, Child T, Granne IE. Human chorionic gonadotrophin priming for fertility treatment with in vitro maturation. Cochrane Database of Systematic Reviews 2016, Issue 11. Art. No.: CD008720. DOI: 10.1002/14651858.CD008720.pub2.

Copyright (c) 2016 The Cochrane Collaboration. Published by John Wiley \& Sons, Ltd.

\section{A B S T R A C T}

\section{Background}

In vitro maturation (IVM) is a fertility treatment that involves the transvaginal retrieval of immature oocytes, and their subsequent maturation and fertilisation. Although the live birth rate is lower than conventional in vitro fertilisation (IVF) with ovarian stimulation, it is a useful treatment, as it avoids the risk of ovarian hyperstimulation syndrome (OHSS). Women with polycystic ovaries (PCO) or polycystic ovarian syndrome (PCOS) are at an increased risk of OHSS. Thus, IVM may be a more useful treatment in this patient group.

Strategies to maximise the maturation rates of the immature oocytes are important. This review focuses on the administration of human chorionic gonadotrophin (hCG) prior to immature oocyte retrieval.

\section{Objectives}

To determine the effectiveness and safety of hCG priming in subfertile women who are undergoing IVM treatment in the context of assisted reproduction.

\section{Search methods}

We searched the following electronic databases up to 29 August 2016: Cochrane Gynaecology and Fertility Group Specialised Register of controlled trials, CENTRAL, MEDLINE, Embase, PsycINFO, and CINAHL. We also searched the trial registries ClinicalTrials.gov and WHO ICTPR to identify ongoing and registered trials. We sought recently published papers not yet indexed in the major databases, and reviewed the reference lists of reviews and retrieved studies as sources of potentially relevant studies. There were no language restrictions.

\section{Selection criteria}

We included randomised controlled trials (RCTs) that compared hCG priming with placebo or no priming in women undergoing IVM. We also included RCTs that compared different doses of hCG, or the timing of oocyte retrieval. The primary outcomes were live birth rate and miscarriage rate per woman randomised.

\section{Data collection and analysis}

Two review authors independently selected studies for inclusion, and with a third author, assessed risk of bias and extracted data. We contacted the original authors where data were missing. For dichotomous outcomes, we used the Mantel-Haenszel method to calculate odds ratios (OR). For continuous outcomes, we calculated the mean differences (MD) between treatment groups. We assessed statistical heterogeneity using the $I^{2}$ statistic. We assessed the overall quality of the evidence using GRADE methods. 


\section{Main results}

We included four studies, with a total of 522 women, in the review. One of these studies did not report outcomes per woman randomised, and so was not included in formal analysis. Three studies investigated 10,000 units hCG priming compared to no priming. One study investigated 20,000 units hCG compared to 10,000 units hCG priming. Three studies only included women with PCOS ( $N=122)$, while this was an exclusion criteria in the fourth study $(\mathrm{N}=400)$.

We rated all four studies as having an unclear risk of bias in more than one of the seven domains assessed. The quality of the evidence was low, the main limitations being lack of blinding and imprecision.

When 10,000 units hCG priming was compared to no priming, we found no evidence of a difference in the live birth rates per woman randomised (OR $0.65,95 \%$ confidence intervals $(\mathrm{Cl}) 0.24$ to 1.74 ; one $\mathrm{RCT} ; \mathrm{N}=82$; low quality evidence); miscarriage rate $(\mathrm{OR} 0.60,95 \% \mathrm{Cl}$ 0.21 to 1.72 ; two RCTs; $\mathrm{N}=282 ; \mathrm{I}^{2}$ statistic = 21\%; low quality evidence), or clinical pregnancy rate (OR $0.52,95 \% \mathrm{Cl} 0.26$ to 1.03 ; two RCTs, $\mathrm{N}$ $=282, \mathrm{I}^{2}$ statistic $=0 \%$, low quality evidence). Though inconclusive, our findings suggested that hCG may be associated with a reduction in clinical pregnancy rates; $22 \%$ of women who received no priming achieved pregnancy, while between $7 \%$ and $23 \%$ of women who received hCG priming did so.

The study comparing 20,000 units hCG with 10,000 units hCG did not report sufficient data to enable us to calculate odds ratios.

No studies reported on adverse events (other than miscarriage) or drug reactions.

\section{Authors' conclusions}

This review found no conclusive evidence that hCG priming had an effect on live birth, pregnancy, or miscarriage rates in IVM. There was low quality evidence that suggested that hCG priming may reduce clinical pregnancy rates, however, these findings were limited by the small number of data included. As no data were available on adverse events (other than miscarriage) or on drug reactions, we could not adequately assess the safety of hCG priming. We need further evidence from well-designed RCTs before we can come to definitive conclusions about the role of hCG priming, and the optimal dose and timing.

\section{PLAIN LANGUAGE SUMMARY}

\section{Human chorionic gonadotrophin (hCG) priming in in vitro maturation (IVM)}

\section{Review Question}

Cochrane authors reviewed the evidence about hCG priming in IVM to determine its effectiveness and safety in subfertile women undergoing assisted reproduction. The main outcomes were live birth and miscarriage rate.

\section{Background}

Assisted reproduction usually involves ovarian stimulation to obtain a higher yield (or number) of oocytes (immature egg cells). One complication of this is ovarian hyperstimulation syndrome (OHSS), which in its most severe form, can cause life threatening complications. Women with polycystic ovaries (PCO) or polycystic ovarian syndrome (PCOS) are at an increased risk of OHSS. In IVM, multiple immature oocytes are retrieved, usually from unstimulated ovaries, prior to subsequent maturation and fertilisation. In vitro maturation has a lower live birth rate than in vitro fertilisation, but it avoids the risk of OHSS, so is a useful technique in women with PCO and PCOS. It is also beneficial for other patient groups, such as women who require urgent fertility preservation prior to cancer treatment, or women who are resistant to ovarian stimulation. Strategies are needed to improve the maturation rate and subsequent live birth rate in IVM. During the normal menstrual cycle, a surge in luteinising hormone (LH) triggers oocyte maturation and ovulation. Human chorionic gonadotrophin has a similar structure to $\mathrm{LH}$, and can mimic its biological activity. Therefore, it can be used to promote the start of oocyte maturation, when given as a trigger prior to oocyte retrieval. This is called hCG priming.

\section{Study Characteristics}

This review included four randomised controlled trials, with a total of 522 women. One study investigated the use of 20,000 units hCG priming compared to 10,000 units. The remaining studies investigated 10,000 units hCG priming compared to no priming. The main outcomes were live birth rate and miscarriage rate per woman randomised. Evidence published up to 29 August 2016 was examined.

\section{Key Results}

Only one study reported the main outcome of live birth per woman randomised; two studies reported clinical pregnancy. We found no certain evidence of a difference between 10,000 units hCG priming and no priming. However, there was some low quality evidence to suggest that hCG may be associated with a reduction in pregnancy rates; $22 \%$ of women who received no priming achieved pregnancy, while between $7 \%$ and $23 \%$ of women who received hCG priming did so. Two studies reported miscarriage rate per woman randomised, and found no evidence of a difference between 10,000 units hCG priming and no priming. No studies reported on adverse events (other than miscarriage) or drug reactions. 
Overall, there was insufficient evidence to draw any definite conclusions on the use of hCG priming in IVM. Further randomised trials are necessary, in particular, focusing on women with PCOS.

\section{Quality of the evidence}

The quality of the evidence was low, the main limitations being imprecision (random error) and lack of blinding (the process in which participant and assessor are prevented from knowing which intervention has been received). 


\begin{tabular}{|c|c|c|c|c|c|c|c|}
\hline \multirow{12}{*}{ 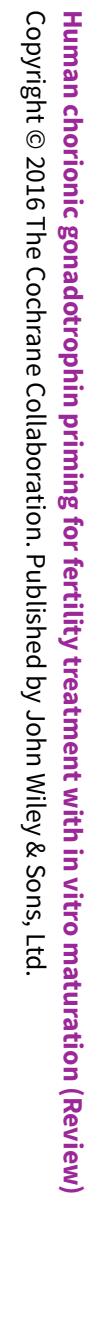 } & \multicolumn{7}{|c|}{$\begin{array}{l}\text { S U M M A R Y O F F I N D I N G S } \\
\text { Summary of findings for the main comparison. Human chorionic gonadotrophin (hCG) priming for subfertile women undergoing in vitro maturation } \\
\text { (IVM) }\end{array}$} \\
\hline & \multicolumn{7}{|c|}{ HCG priming versus no priming in women undergoing IVM treatment for subfertility } \\
\hline & \multicolumn{7}{|c|}{$\begin{array}{l}\text { Population: Subfertile women undergoing in vitro maturation } \\
\text { Setting: Assisted reproduction clinic } \\
\text { Intervention: } 10,000 \text { units hCG } \\
\text { Comparison: No priming }\end{array}$} \\
\hline & \multirow[t]{2}{*}{ Outcomes } & \multicolumn{2}{|c|}{ Anticipated absolute effects* $(95 \% \mathrm{Cl})$} & \multirow{2}{*}{$\begin{array}{l}\text { Relative effect } \\
(95 \% \mathrm{Cl})\end{array}$} & \multirow{2}{*}{$\begin{array}{l}\text { No. of partici- } \\
\text { pants } \\
\text { (studies) }\end{array}$} & \multirow{2}{*}{$\begin{array}{l}\text { Quality of the } \\
\text { evidence } \\
\text { (GRADE) }\end{array}$} & \multirow[t]{2}{*}{ Comments } \\
\hline & & Risk with no & Risk with 10,000 units hCG & & & & \\
\hline & \multirow[t]{2}{*}{ Live Birth Rate } & Moderate (me & & \multirow{2}{*}{$\begin{array}{l}\text { OR } 0.65 \\
(0.24 \text { to } 1.74)\end{array}$} & \multirow{2}{*}{$\begin{array}{l}82 \\
(1 \mathrm{RCT})\end{array}$} & \multirow{2}{*}{$\begin{array}{l}\oplus \oplus \Theta \ominus \\
\operatorname{LOW} 1,2\end{array}$} & \\
\hline & & 310 per 1000 & $\begin{array}{l}226 \text { per } 1000 \\
\text { (97 to } 439)\end{array}$ & & & & \\
\hline & \multirow[t]{2}{*}{ Miscarriage Rate } & Moderate (me & & \multirow{2}{*}{$\begin{array}{l}\text { OR } 0.60 \\
(0.21 \text { to } 1.72)\end{array}$} & \multirow{2}{*}{$\begin{array}{l}282 \\
\text { (2 RCTs) }\end{array}$} & \multirow{2}{*}{\multicolumn{2}{|c|}{$\begin{array}{l}\oplus \oplus \Theta \odot \\
\text { LOW } 1,2\end{array}$}} \\
\hline & & 70 per 1000 & $\begin{array}{l}43 \text { per } 1000 \\
(16 \text { to } 115)\end{array}$ & & & & \\
\hline & \multirow{2}{*}{$\begin{array}{l}\text { Clinical Pregnancy } \\
\text { Rate }\end{array}$} & \multicolumn{2}{|c|}{ Moderate (median) risk } & \multirow{2}{*}{$\begin{array}{l}\text { OR } 0.52 \\
\text { (0.26 to } 1.03)\end{array}$} & \multirow{2}{*}{$\begin{array}{l}282 \\
(2 \mathrm{RCTs})\end{array}$} & \multirow{2}{*}{\multicolumn{2}{|c|}{$\begin{array}{l}\oplus \oplus \ominus \ominus \\
\text { LOW } 1,2\end{array}$}} \\
\hline & & 225 per 1000 & $\begin{array}{l}131 \text { per } 1000 \\
\text { (70 to } 230)\end{array}$ & & & & \\
\hline & $\begin{array}{l}\text { Adverse events and } \\
\text { drug reactions }\end{array}$ & \multicolumn{6}{|c|}{ No study reported data on any adverse events (apart from miscarriage) nor on drug reactions } \\
\hline
\end{tabular}

${ }^{\star}$ The risk in the intervention group (and its $95 \%$ confidence interval) is based on the assumed risk in the comparison group and the relative effect of the intervention (and its $95 \% \mathrm{Cl})$.

Cl: Confidence interval; RR: Risk ratio; OR: Odds ratio;

\section{GRADE Working Group grades of evidence}

High quality: We are very confident that the true effect lies close to that of the estimate of the effect

Moderate quality: We are moderately confident in the effect estimate: The true effect is likely to be close to the estimate of the effect, but there is a possibility that it is substantially different

Low quality: Our confidence in the effect estimate is limited: The true effect may be substantially different from the estimate of the effect 


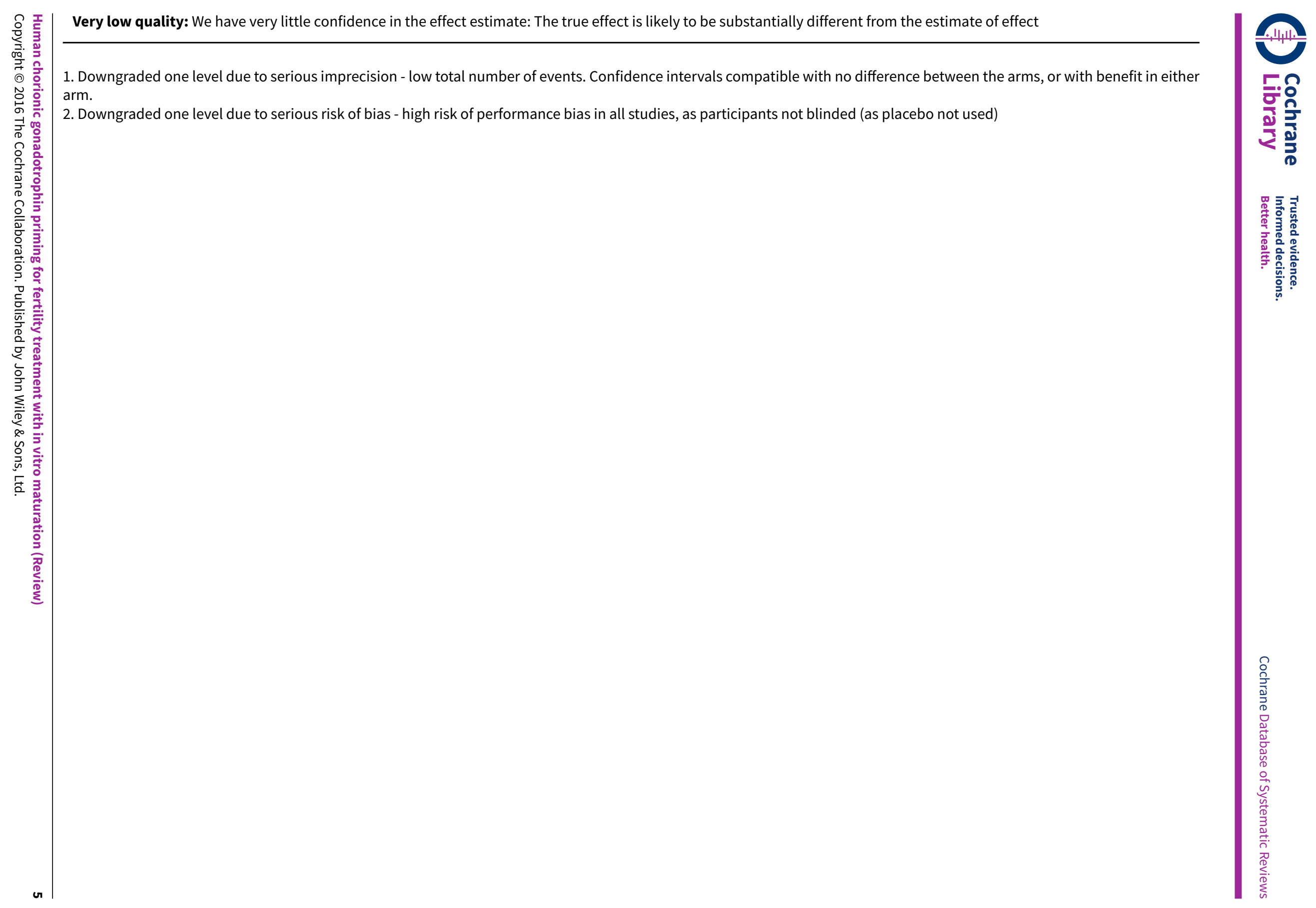




\section{B A C K G R O U N D}

\section{Description of the condition}

It is estimated that subfertility affects one in seven couples in the UK. In approximately $25 \%$ of subfertile women, this is due to ovulatory dysfunction, which is primarily caused by polycystic ovarian syndrome (PCOS (NICE 2013)). Women are diagnosed with PCOS if they meet two of the three following Rotterdam Consensus Criteria: 1. Polycystic ovary appearance (PCO) on ultrasound scan (either 12 or more follicles, or ovarian volume greater than 10 $\left.\mathrm{cm}^{3}\right)$; 2. Oligo-ovulation or anovulation; 3. Clinical or biochemical signs (or both) of hyperandrogenism (Rotterdam 2003). Women with PCOS or PCO (ultrasound appearance seen but not meeting full diagnostic criteria) who are undergoing assisted reproductive techniques are at an increased risk of ovarian hyperstimulation syndrome (OHSS), with described rates of $15.4 \%$ for PCOS and $12.6 \%$ for PCO, compared to $2.7 \%$ in those with normal ovaries (Swanton 2010).

Ovarian hyperstimulation syndrome is a potentially life threatening complication of fertility treatment when pharmacological ovarian stimulation is performed. When exposed to human chorionic gonadotrophin (hCG), the hyperstimulated ovaries release vasoactive substances, which cause increased vascular permeability. This results in fluid leaking from intravascular to extravascular compartments, with subsequent intravascular depletion and third-space fluid accumulation. The severity can range from mild abdominal pain and bloating to life threatening complications that include renal failure, thromboembolism, and acute respiratory distress syndrome.

The incidence of OHSS varies between different types of fertility treatment. In conventional in vitro fertilisation (IVF), the combined incidence of moderate to severe OHSS varies from $3.1 \%$ to $8 \%$ (Delvigne 2002). In addition to PCOS and PCO, other patient characteristics have been found to increase the risk of OHSS, including a previous history of OHSS and younger age.

Other factors seen during ovarian stimulation, such as high serum estradiol and high follicle numbers, have been correlated with an increased risk. The incidence is also higher when high dose gonadotrophin stimulation regimens are used. A number of strategies can be used to reduce OHSS. Using gonadotrophinreleasing hormone $(\mathrm{GnRH})$ antagonists rather than $\mathrm{GnRH}$ agonists as part of the regimen for controlled ovarian stimulation has been shown, by meta-analysis, to reduce the OHSS risk (Al-Inany 2011). Coasting can also be used, a process in which gonadotrophin injections are stopped, while pituitary suppression continues. This leads to atresia of the small and intermediate-sized follicles, with a subsequent fall in serum estradiol levels. Only when serum estradiol falls, is the hCG trigger for maturation given. This has been shown in observational studies to reduce OHSS risk (Al-Shawaf 2001).

Other strategies include abandoning the cycle prior to hCG administration and oocyte collection, and using a GnRH agonist rather than hCG for the final maturation of oocytes.

An alternate treatment option is in vitro maturation (IVM). This involves the transvaginal retrieval of immature oocytes during the germinal vesicle stage. Oocyte maturation is subsequently performed in vitro or in laboratory controlled conditions, up to the metaphase II phase, when the oocytes can then undergo fertilisation. Although the live birth rate after IVM is lower than that of conventionally stimulated in vitro fertilisation, it avoids the risk of OHSS, and therefore, is of particular value in women who have previously experienced severe OHSS (Child 2002). In vitro maturation is also an effective treatment option for women with PCOS or PCO who are at a higher risk of OHSS, in whom it has produced similar outcome rates to women without PCOS (Siristatidis 2015). Additional indications for IVM include women with ovarian resistance to gonadotrophins, those who have previously been high responders to ovarian stimulation, and women who require urgent fertility preservation prior to chemotherapy or radiotherapy.

\section{Description of the intervention}

Success rates after IVM are likely to be higher in women with PCO or PCOS, because the pregnancy rate has been shown to be significantly related to the number of immature oocytes retrieved (Child 2001); this can be predicted by ultrasonic evaluation of antral follicle count (Tan 2002). It has been shown that immature oocytes from women with PCOS can retain their maturational and developmental competence (Trounson 1994). However, the maturation rate of immature oocytes from women with PCOS is known to be less than from women with normal menstrual cycles (Cha 1998). Therefore, strategies for maximizing maturation rates and improving clinical outcomes for IVM are important.

The use of hCG is one strategy that has been used. During the normal menstrual cycle, a surge in luteinising hormone (LH) causes both the resumption of meiosis and triggers ovulation. Human chorionic gonadotrophin (a hormone produced by the developing embryo and later, the placenta) is structurally very similar to LH, and mimics its biological activity. Therefore, hCG can be used therapeutically to promote the start of oocyte maturation in smaller ovarian follicles. This process is termed hCG priming and involves the administration of a subcutaneous dose of hCG prior to immature oocyte retrieval. This is usually given 34 to 38 hours before retrieval. Usual doses of hCG are 5000 to 10,000 units, although higher doses, up to 20,000 units, may be administered.

\section{How the intervention might work}

It has been shown that immature oocytes with dispersed cumulus cells (rather than sparse or compacted cells) show better rates of maturation and better embryo potential. The presence of oocytes with dispersed cumulus cells at the time of IVM oocyte collection has been associated with hCG priming (Son 2005; Yang 2005). Therefore, the precise timing or dose of hCG may alter the number of oocytes reaching maturity after IVM, and consequently may alter the pregnancy and live birth outcomes in subfertile women undergoing IVF or assisted reproduction.

\section{Why it is important to do this review}

There is no clear consensus as to whether hCG priming influences the effectiveness of IVM in subfertile women, or whether it is safe. It is also unclear what dose of hCG should be used, or when oocyte collection should be performed in relation to a hCG trigger.

\section{OB JECTIVES}

To determine the effectiveness and safety of human chorionic gonadotrophin (hCG) priming in subfertile women who are 
undergoing in vitro maturation (IVM) treatment in the context of assisted reproduction.

\section{METHODS}

\section{Criteria for considering studies for this review}

\section{Types of studies}

In this review, we included only randomised controlled trials (RCTs) that investigated hCG priming in women undergoing IVM treatment.

\section{Types of participants}

Women undergoing IVM treatment for subfertility. There were no exclusion criteria.

\section{Types of interventions}

1. Studies comparing hCG with placebo priming

2. Studies comparing hCG with no priming

3. Studies comparing different doses of hCG

4. Studies comparing the timing of hCG administration prior to oocyte retrieval

\section{Types of outcome measures}

\section{Primary outcomes}

1. Live birth rate per woman randomised (live birth was defined as a live birth after 24 completed weeks gestation)

2. Miscarriage rate per woman randomised

\section{Secondary outcomes}

3. Clinical pregnancy rate per woman randomised (clinical pregnancy was defined as the presence of a fetal heart on ultrasound after six weeks gestation)

4. Drug reactions per woman randomised

5. Adverse events per woman randomised

6. Number of oocytes retrieved per woman randomised

7. Mean percentage of mature oocytes at 0 hours as a proportion of oocytes retrieved from each randomised woman

8. Mean percentage of oocytes at metaphase II after 24 hours as a proportion of oocytes retrieved from each randomised woman

9. Mean percentage of oocytes at metaphase II after 48 hours as a proportion of oocytes retrieved from each randomised woman

10. Mean percentage of oocytes fertilised as a proportion of mature oocytes available from each randomised woman

11. Mean percentage of embryos cleaved as a proportion of oocytes fertilised from each randomised woman

12. Mean percentage of embryos implanted as a proportion of embryos transferred from each randomised woman

\section{Search methods for identification of studies}

We used the following search strategies in consultation with the Cochrane Gynaecology and Fertility Group Information Specialist.
There were no language restrictions on the searches and no restriction on publication status.

\section{Electronic searches}

We searched the following databases (see Appendix 1):

- Gynaecology and Fertility Group's Specialised Register of controlled trials (from inception to 29 August 2016)

- The Cochrane Central Register of Controlled Trials (CENTRAL) via the Cochrane Register of Studies online (CRSO; from inception to 29 August 2016)

- MEDLINE (from 1946 to 29 August 2016)

- Embase (from 1974 to 29 August 2016)

- PsycINFO (from 1806 to 29 August 2016)

- CINAHL (from 1982 to 29 August 2016)

\section{Searching other resources}

In order to obtain additional relevant data, we handsearched the reference lists from included articles. We contacted the study authors if necessary. We searched for ongoing and registered trials in the trial registries www.clinicaltrials.gov and The World Health Organization International Clinical Trials Registry Platform (ICTRP). We conducted a search of PubMed and Google Scholar (from 13 February 2015 to 15 August 2016) to identify papers recently published but not yet indexed in the major databases. We identified reviews and searched their reference lists as sources of potentially relevant studies. We also handsearched the European Society of Human Reproduction and Embryology (ESHRE) conference abstracts from 2014 to 2016 for potentially relevant unpublished reports.

\section{Data collection and analysis}

\section{Selection of studies}

We developed forms for inclusion criteria (Appendix 2), data extraction (Appendix 3), and 'Risk of bias' assessment (Appendix 4).

Two review authors (IG and JR) independently screened the titles and abstracts of the studies identified by the search. They used the established criteria to select eligible studies. They excluded studies that were clearly not applicable and obtained the full texts of all potentially eligible studies. Where there were insufficient data to make a decision, they contacted the study authors for further information. No disagreements about selection occurred, but they had planned to refer to a third review author (KV or TC) to resolve disagreements if required.

Two review authors independently reviewed the included trials for risk of bias, and extracted the data. For studies that did not satisfy the inclusion criteria, they noted the reasons for exclusion in the 'Characteristics of excluded studies' table. They completed a similar 'Characteristics of included studies' table for studies that were considered suitable.

\section{Data extraction and management}

Two review authors (IG and JR) independently extracted data from the included studies, using the data extraction form Appendix 3. They compared the two sets of extracted data, and resolved discrepancies by discussion with KV. 


\section{Assessment of risk of bias in included studies}

The review authors independently assessed the risk of bias with the Cochrane 'Risk of bias' assessment tool, and with the aid of a detailed data extraction form (Higgins 2011; Appendix 4). Two review authors (IG and JR) independently classified each 'risk of bias' domain as low, high, or unclear. They resolved any disagreement by discussion with $\mathrm{KV}$.

They considered these domains of bias:
- Sequence generation;

- Allocation concealment;

- Blinding (participants and personnel);

- Incomplete outcome data;

- Selective outcome reporting;

- Any other bias.

All judgements are described in the "Risk of bias" tables. A summary of the conclusions are shown in Figure 1 and Figure 2.

Figure 1. Risk of bias graph: review authors' judgements about each risk of bias domain presented as percentages across all included studies.

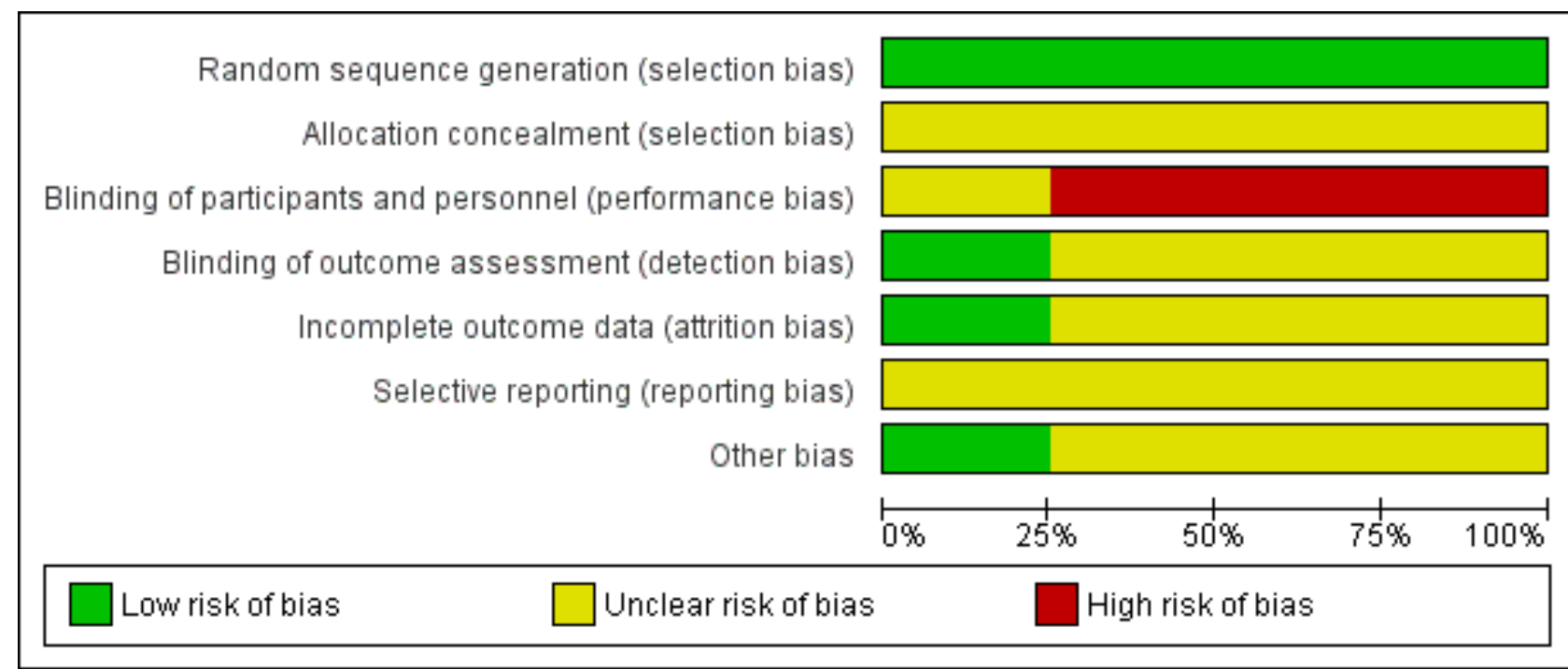


Figure 2. Risk of bias summary: review authors' judgements about each risk of bias domain for each included study.

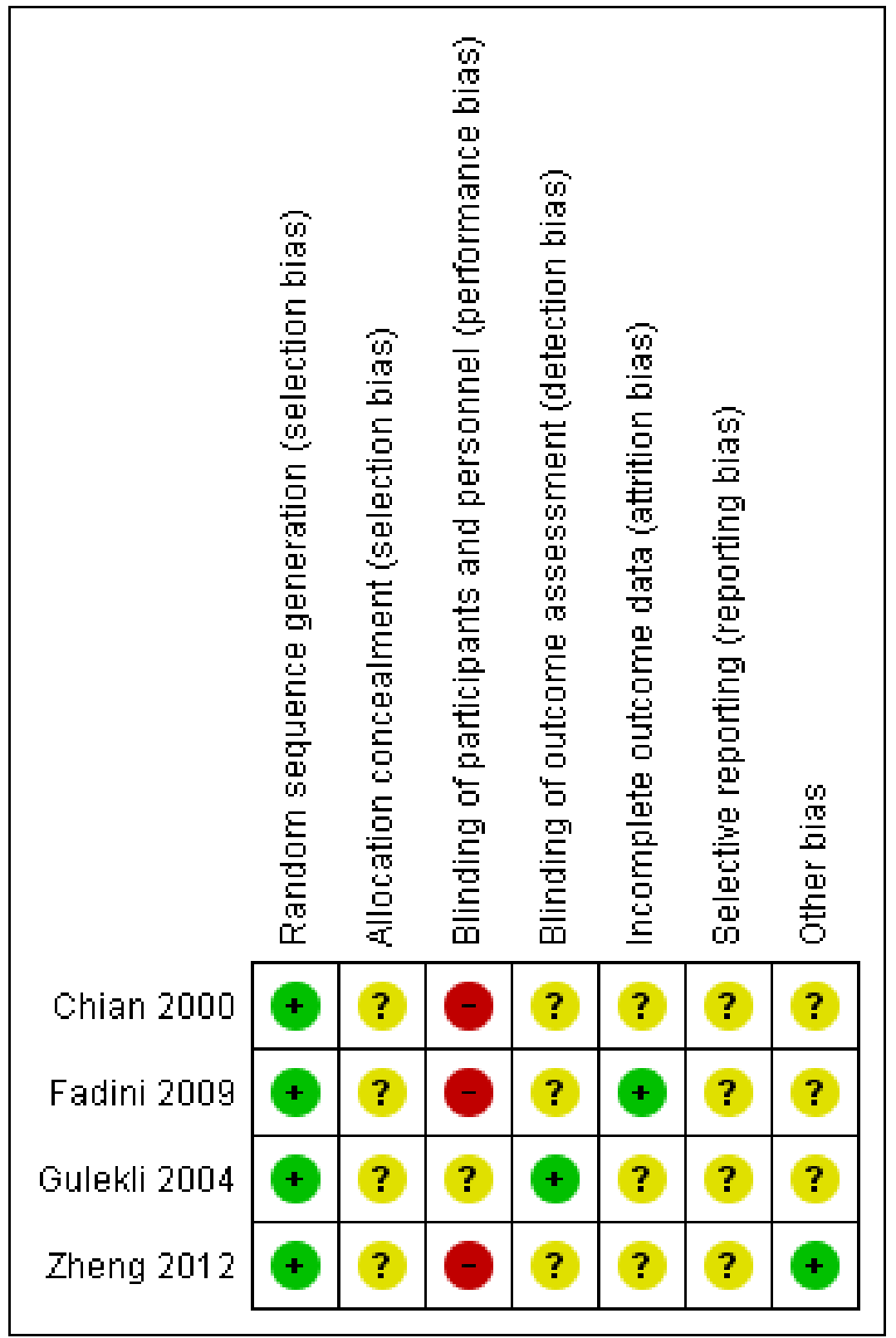

\section{Measures of treatment effect}

We entered the data from the included studies into the RevMan 5.3 software (RevMan 2014). We performed statistical analysis in accordance with the guidelines developed by Cochrane. For dichotomous data (for example live birth rate), we expressed results for each study as odds ratios (OR) with 95\% confidence intervals $(\mathrm{Cl})$, using the Mantel-Haenszel method. For continuous data, we calculated mean differences (MD) between treatment groups, with $95 \%$ Cls. We presented data not suitable for formal analysis in separate tables.

\section{Unit of analysis issues}

We only pooled data from studies that reported outcomes per woman randomised, in order to avoid analysis errors. In the cases of multiple gestation, we considered live birth in the analysis as one live birth event. We presented the data from studies not suitable for formal analysis, either because outcomes were not comparable or not expressed per woman randomised, in separate tables.

\section{Dealing with missing data}

Where data were missing or unclear, we asked trial authors via email to provide further details. The authors of two of the studies responded (Chian 2000; Gulekli 2004). However, in the other cases, we received no response. For participants without a reported outcome, we assumed that live birth did not occur. For all other outcomes, we analysed only the available data.

\section{Assessment of heterogeneity}

We determined heterogeneity by visual inspection of the outcome tables and forest plots. We used the $\mathrm{I}^{2}$ statistic to quantify any 
apparent inconsistency. We interpreted that an $\mathrm{I}^{2}$ statistic of $50 \%$ or more indicated substantial heterogeneity (Higgins 2011).

\section{Assessment of reporting biases}

If there had been sufficient data, we had planned to include funnel plots as an appendix, which may have graphically depicted publication bias if asymmetry had been seen. The review authors are aware that there are other sources of asymmetry in funnel plots (Stuck 1998). If published protocols had been available, we had planned to assess within-study reporting biases by comparing differences between published protocols and the published studies.

\section{Data synthesis}

We combined the data from primary studies using fixed-effect models in these comparisons:

1. Studies comparing hCG with placebo priming

2. Studies comparing hCG with no priming

3. Studies comparing different doses of hCG

4. Studies comparing timing of hCG administration prior to oocyte retrieval.

\section{Subgroup analysis and investigation of heterogeneity}

If we had detected substantial heterogeneity, we had planned to explore possible explanations in subgroup analyses (e.g. different populations), sensitivity analyses (e.g. differing risks of bias), or both. We had planned to take any statistical heterogeneity into account when interpreting the results, especially if there were variations in the direction of effect.

If data had been sufficient, we had planned to conduct subgroup analyses within the following subgroups:

- number of embryos transferred

- more than three previous failed assisted reproductive technology (ART) cycles

- maternal age (up to 35 years, 35 to 40 years, older than 40 years)

- duration of treatment

We performed a post hoc subgroup analysis, stratifying data by PCOS status, for the outcomes of live birth rate, miscarriage rate, and pregnancy rate.

\section{Sensitivity analysis}

If data had been sufficient, we had planned to perform a sensitivity analysis for the primary outcomes to consider whether results would have been different if:

1. A random-effects model had been used

2. Eligibility had been restricted to studies judged to have a low risk of bias

We performed a post hoc sensitivity analysis for the primary outcome of miscarriage rate, analysing data per pregnancy.

\section{Overall quality of the body of evidence: 'Summary of findings' table}

We created a 'Summary of findings' table using GRADEPRO Guideline Development Tool software (GRADEpro GDT 2015). This table evaluated the overall quality of the evidence for the comparison of 10,000 units hCG priming versus no priming, for the outcomes of live birth rate, miscarriage rate, clinical pregnancy rate, and adverse events. We used the five GRADE criteria (i.e. study limitations such as risk of bias, consistency of effect, imprecision, indirectness, and publication bias). Two review authors independently graded the quality of the evidence using Cochrane methods; judgements were documented and justified (Higgins 2011).

\section{RE S U L T S}

\section{Description of studies}

See Characteristics of included studies; Characteristics of excluded studies.

\section{Results of the search}

The search identified 530 articles; one extra study was identified through the references of another record. After removal of duplicates, there were 341 articles left for screening. We initially discarded 329 articles, which were clearly irrelevant. One study was ongoing and had not yet reported results. For the remaining 11 articles, the full texts were obtained and fully reviewed.

We included a total of four studies (eight articles). See Figure 3 for the study flow diagram, which presents the screening and selection process. 
Figure 3. Study Flow Diagram

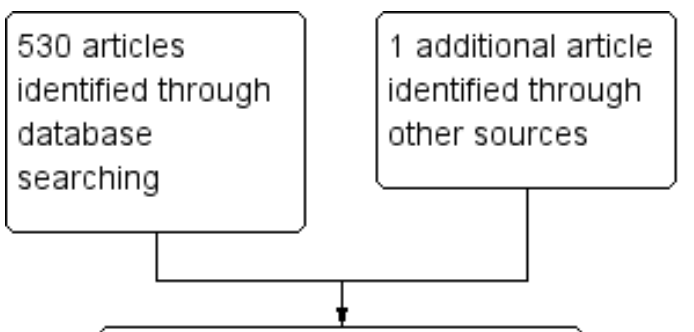

341 articles after duplicates removed

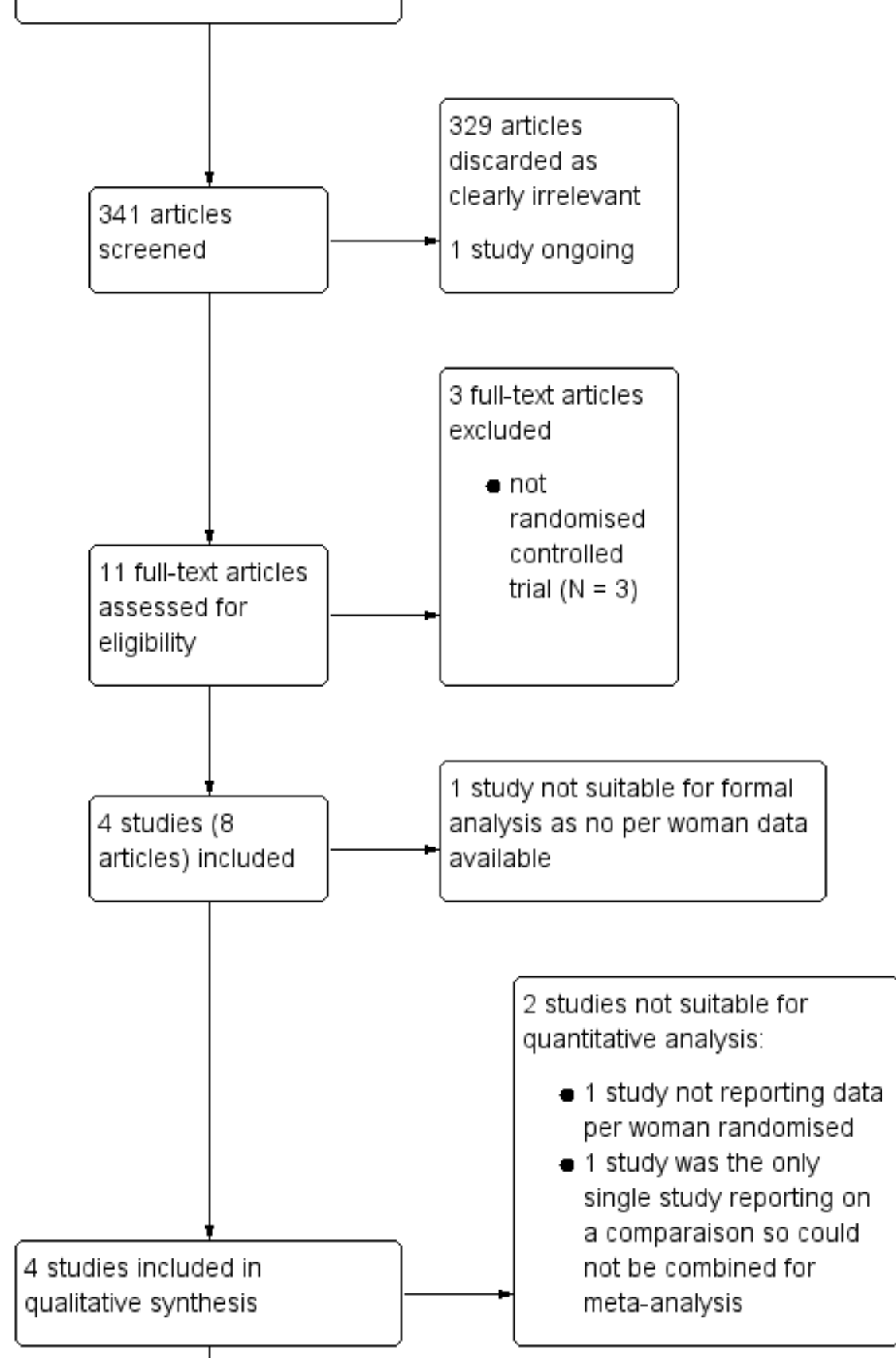


Figure 3. (Continued)

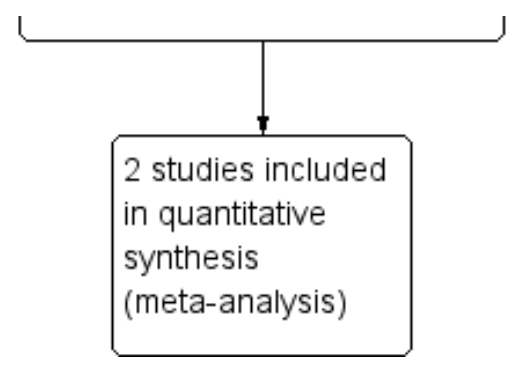

\section{Included studies}

\section{Study Design and Setting}

We included four studies, all single centre studies. Two of the included studies were carried out in Canada (Chian 2000; Gulekli 2004); one study was performed in Italy (Fadini 2009), and one in China (Zheng 2012).

One of the included studies did not report data suitable for analysis, as some women were randomised into the study more than once (Chian 2000). We summarised the data from this study in Table 1.

\section{Participants}

The studies included a total of 522 women. The inclusion and exclusion criteria of the studies varied. Three of the studies only included women with polycystic ovarian syndrome (Chian 2000; Gulekli 2004; Zheng 2012). However, this was an exclusion criterion in Fadini 2009. In two of the studies, women had failed to conceive after at least six previous cycles of ovulation induction (Chian 2000; Gulekli 2004). One study included women who had failed to conceive after only one or no previous cycles of conventional IVF, IVM, or both (Fadini 2009). Zheng 2012 did not comment on previous treatment cycles. All participants were younger than 41 years. We have provided the full details of each study's inclusion and exclusion criteria in the Characteristics of included studies tables.

\section{Interventions}

Three studies investigated the use of 10,000 units hCG for priming versus no priming prior to oocyte retrieval (Chian 2000; Fadini 2009; Zheng 2012). One study investigated different doses of hCG, comparing priming with 10,000 units versus 20,000 units (Gulekli 2004). The largest study had four intervention arms, only two of which were included in the review (Fadini 2009). All studies administered hCG between 36 and 38 hours before oocyte retrieval. In one study, no more than three oocytes per cycle were used, in accordance with Italian law (Fadini 2009). All studies used intracytoplasmic sperm injection (ICSI) for fertilisation. No more than three embryos were transferred in three of the studies (Fadini 2009; Gulekli 2004; Zheng 2012). Chian 2000 did not comment on the number of embryos transferred, but the mean number reported was less than three.

\section{Outcomes}

\section{Primary outcomes}

The primary outcomes for this Cochrane review were live birth rate and miscarriage rate per woman randomised. Only one study reported on live birth rate in the comparison of 10,000 units hCG priming versus no priming (Zheng 2012). Two studies comparing 10,000 units hCG priming to no priming reported on miscarriage rate (Fadini 2009; Zheng 2012).

\section{Secondary outcomes}

Two studies reported on clinical pregnancy rate for the comparison of 10,000 units $h C G$ versus no priming (Fadini 2009; Zheng 2012). No studies reported on drug reactions or adverse effects.

\section{Excluded studies}

Three studies were excluded, since when reviewed in detail, it was clear that they were not randomised controlled trials (Chian 2001; Kim 2013; Son 2001). See Characteristics of excluded studies table.

\section{Ongoing Study}

One study was identified through the trial registries (ISRCTN17078060). It was described as a randomised controlled trial investigating hCG priming versus no priming, 36 hours before aspiration of oocytes, in women with PCOS undergoing IVM treatment. We attempted to contact the author to obtain any preliminary results, but unfortunately this proved unsuccessful. See Characteristics of ongoing studies.

\section{Risk of bias in included studies}

We judged the risk of bias in the included studies (see Characteristics of included studies). See the risk of bias graph (Figure 1), and the risk of bias table (Figure 2), for details.

\section{Allocation}

All four studies used a computerised random table and were rated to be at low risk of bias for random sequence generation.

The method of allocation concealment was only reported in one study, which used a sealed envelope (Gulekli 2004). However, they did not state whether this was an opaque envelope, so it was rated as an unclear risk of bias. The other studies did not comment on allocation concealment, so risk of bias was also rated as unclear.

\section{Blinding}

Two studies mentioned that they used blinding (Gulekli 2004; Zheng 2012). The other studies did not comment on the use of blinding (Chian 2000; Fadini 2009). However, it was not possible for the participants to be blinded, as those in the control group received no placebo. Therefore, they were judged to be at high risk of performance bias. Gulekli 2004 was judged at low risk of detection bias, as both the clinician performing oocyte retrieval and the embryologist were unaware of the dose used. Zheng 2012 reported that the patients and embryologist were blinded. 
However, it is unclear how the patients could have been blinded as they did not report using a placebo injection.

\section{Incomplete outcome data}

Only one study reported the number of, and reasons for withdrawal, and included a flow diagram to illustrate this (Fadini 2009). Intention-to-treat analysis was also used in this study. The other studies gave no information on withdrawal and therefore, were judged to have an unclear risk of attrition bias.

\section{Selective reporting}

We did not find a registered protocol with prespecified outcomes for any of the included studies. Therefore, they were all judged to have an unclear risk of bias.

\section{Other potential sources of bias}

Zheng 2012 was the only study to report its funding, and declared no competing interests. The remaining studies did not comment on this, and therefore were judged at unclear risk of bias, due to insufficient information.

One study reported rates per cycle rather than per woman randomised; these data were not included in the review analysis, and so were not regarded as a source of bias (Chian 2000).

We aimed to retrieve all eligible studies. However, there might be some studies that were not yet published at the time of our search.
We were unable to assess for publication bias with a funnel plot, as we identified too few studies.

\section{Effects of interventions}

See: Summary of findings for the main comparison Human chorionic gonadotrophin (hCG) priming for subfertile women undergoing in vitro maturation (IVM)

See Summary of findings table (Summary of findings for the main comparison) for the results of 10,000 units hCG priming versus no priming.

\section{HCG priming versus placebo priming}

No studies reported this comparison

\section{HCG priming versus no priming}

Studies reporting this outcome compared 10,000 units hCG to no priming.

\section{Primary outcome:}

\subsection{Live birth rate (defined as a live birth rate after 24 completed weeks gestation)}

Only one study reported live birth rate per woman randomised (Zheng 2012). The women in this study all had PCOS. There was no evidence of a difference between the groups (OR 0.65, 95\% Cl 0.24 to $1.74 ; \mathrm{N}=82$; low-quality evidence). See Analysis 1.1; Figure 4.

\section{Figure 4. Forest plot of comparison: 10,000 units hCG priming versus no priming, outcome: Live birth rate}

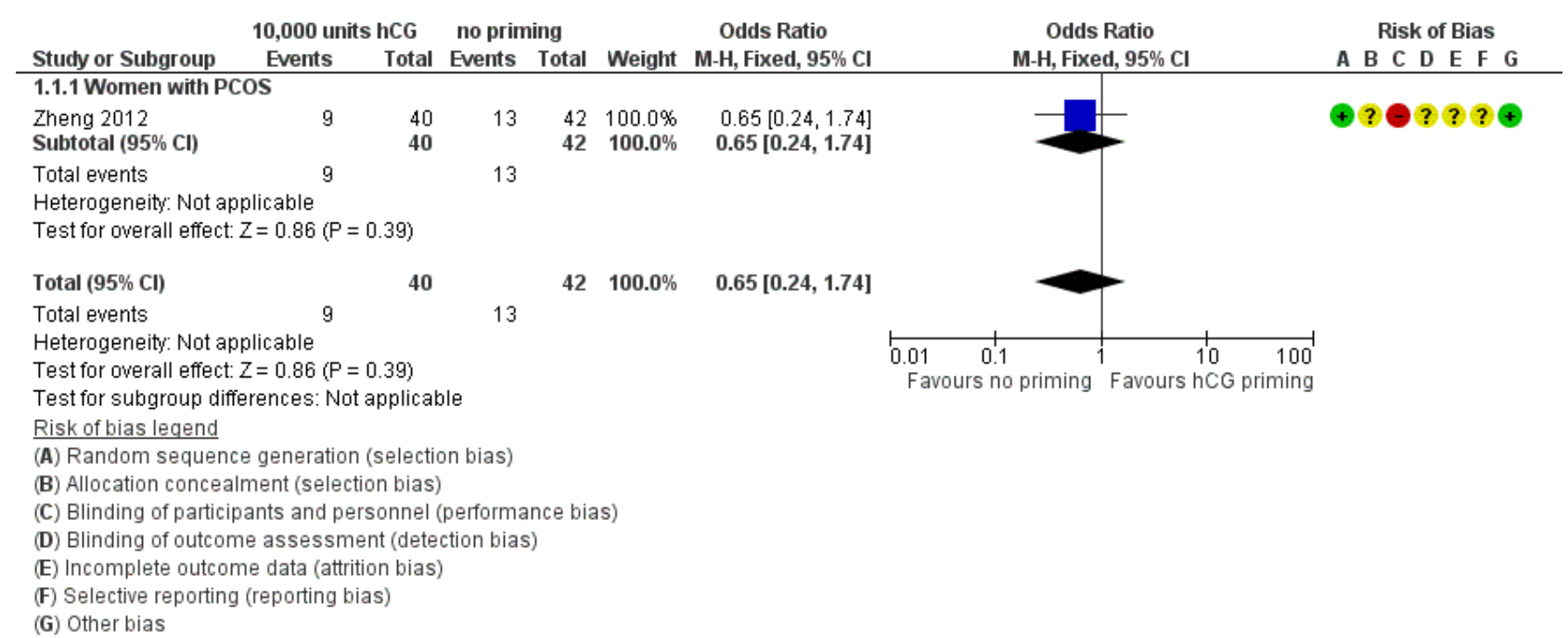

Fadini 2009 reported total live birth rate, but information was not available for each individual group.

Chian 2000 reported on this outcome, but not per woman randomised (Table 1 ). The study authors found no evidence of a difference between groups, reporting on three live births from 13 cycles with hCG priming, and three live births from 11 cycles with no priming.

\subsection{Miscarriage rate}

Two studies reported miscarriage rate per woman randomised, and found no evidence of difference between the groups (OR 0.60, 95\% $\mathrm{Cl} 0.21$ to $1.72 ; \mathrm{N}=282 ; \mathrm{I}^{2}=0 \%$; low quality evidence; Fadini 2009; Zheng 2012). See Analysis 1.2; Figure 5. Miscarriage rate was also subgrouped into PCOS status. One trial included women with PCOS (Zheng 2012); no evidence of treatment effect was seen (OR 0.75, $95 \% \mathrm{Cl} 0.24$ to $2.39 ; \mathrm{N}=82$ ). Women without PCOS were included in the other study, which also showed no evidence of treatment effect in this subgroup (OR 0.20, 95\% Cl 0.01 to 4.14; $\mathrm{N}=200$; Fadini 2009). 
Figure 5. Forest plot of comparison: 10,000 units hCG priming versus no priming, outcome: Miscarriage rate

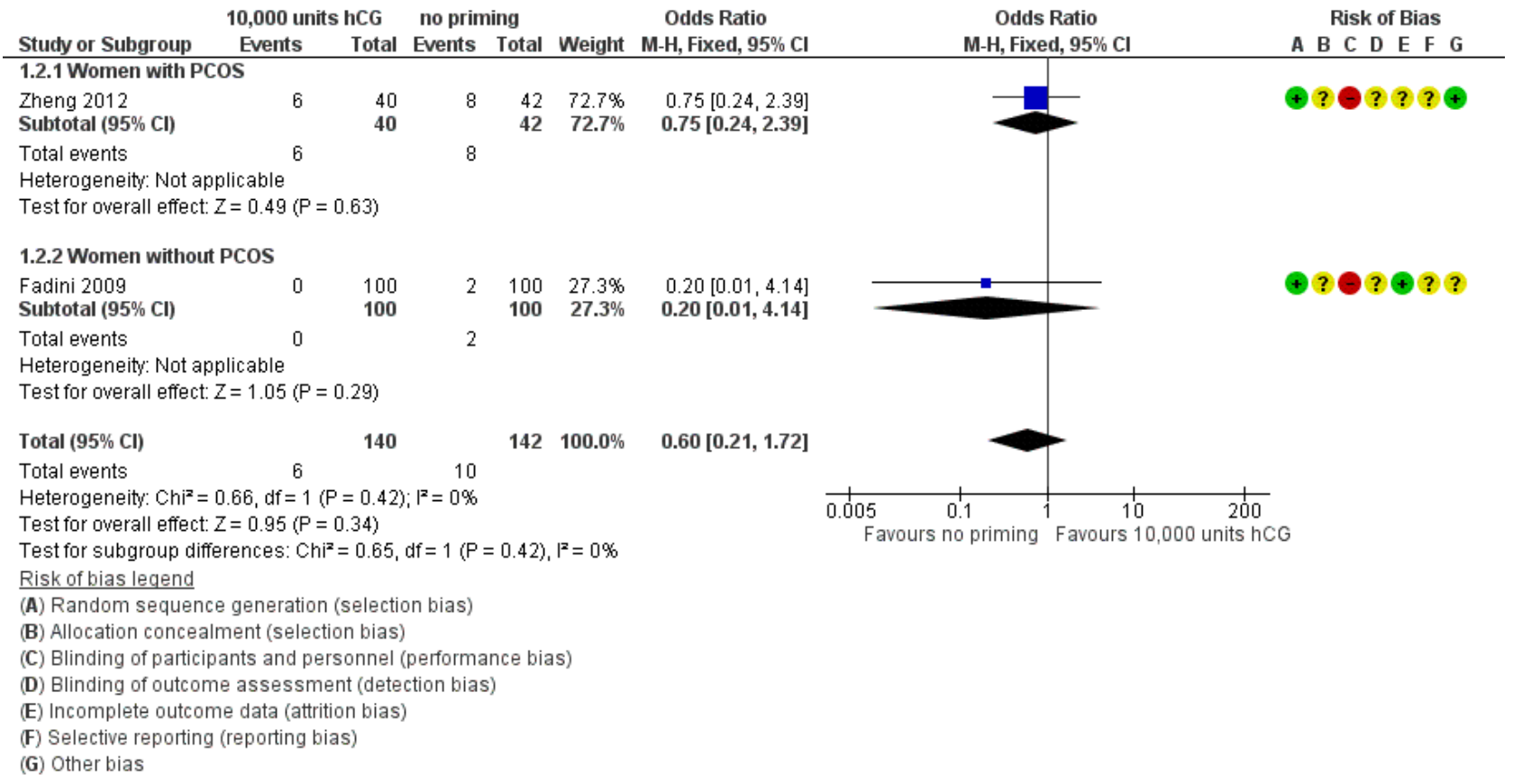

A sensitivity analysis to explore the miscarriage rate per pregnancy (rather than per woman randomised) increased the $\mathrm{Cl}$ but did not change the outcome (OR $0.88,95 \% \mathrm{Cl} 0.26$ to $\left.2.98 ; \mathrm{N}=52 ; \mathrm{I}^{2}=0 \%\right)$.

Chian 2000 was not included in the formal analysis as results were not expressed per woman randomised. However, the study authors reported on two miscarriages from the five clinical pregnancies achieved with hCG priming, and no miscarriages in the three clinical pregnancies in which no priming was used.

\section{Secondary outcomes:}

2.3 Clinical pregnancy rate (defined as the presence of a fetal heart on ultrasound after six weeks gestation)

Two studies reported clinical pregnancy rate per woman randomised (Fadini 2009; Zheng 2012). However, they did not define it as the presence of a fetal heart on ultrasound after six weeks gestation, but rather as the presence of a gestational sac with or without a fetal heartbeat. Our findings, though inconclusive, suggested that hCG may be associated with a reduction in pregnancy rates (OR $0.52,95 \% \mathrm{Cl} 0.26$ to $1.03 ; 2$ studies; $\mathrm{N}=282 ; \mathrm{I}^{2}$ $=0 \%$; low quality evidence). See Analysis 1.3; Figure 6 . 
Figure 6. Forest plot of comparison: 10,000 units hCG priming versus no priming, outcome: Clinical pregnancy rate.

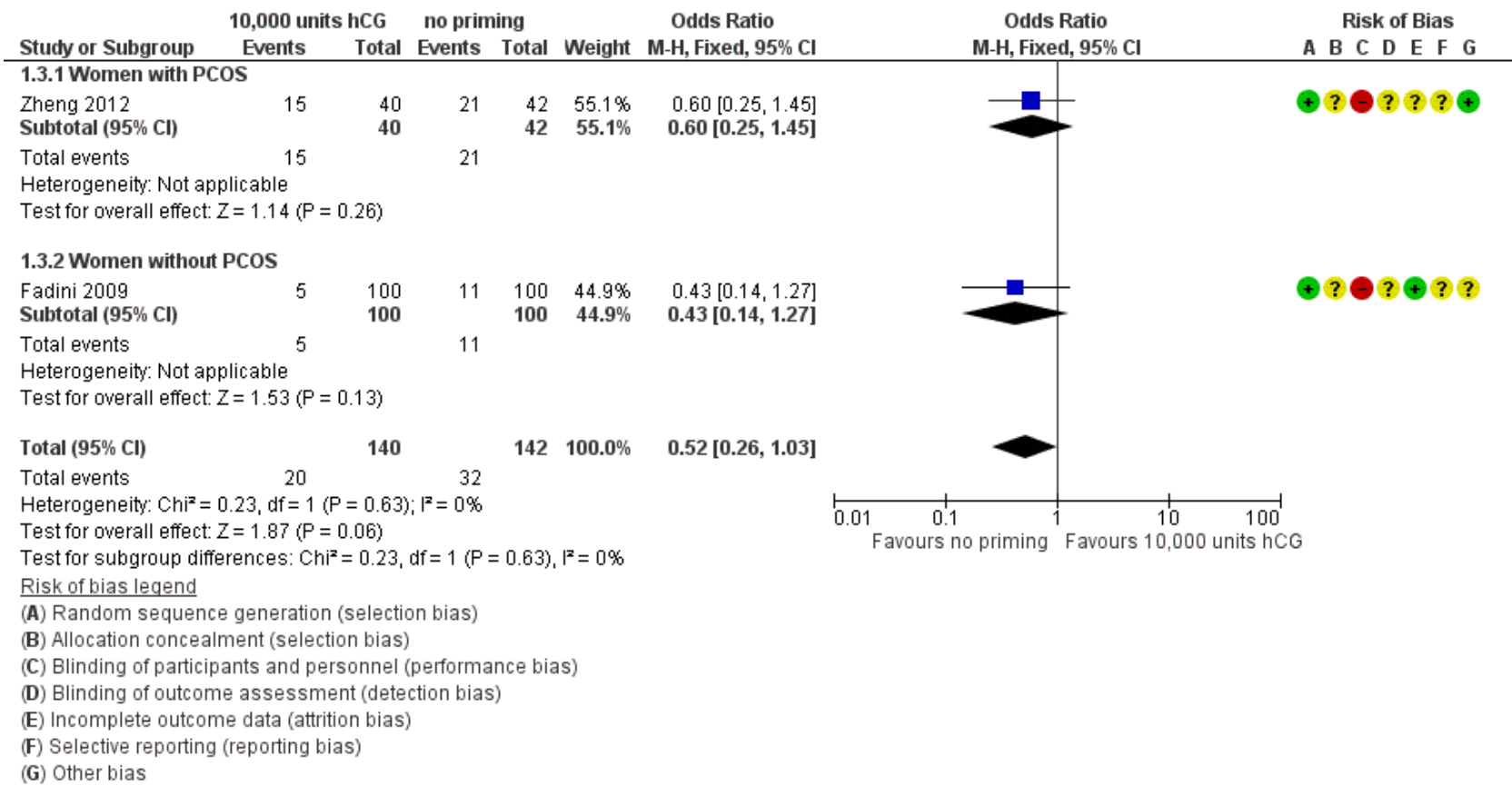

The clinical pregnancy rates were also subgrouped by PCOS status. No evidence of treatment effect was seen with hCG priming in the study that included women with PCOS (OR $0.60,95 \% \mathrm{Cl} 0.25$ to 1.45 ; $\mathrm{N}=82$; Zheng 2012). There was also no evidence of treatment effect for this outcome in women without PCOS (OR $0.43,95 \% \mathrm{Cl} 0.14$ to 1.27 ; $=200$; Fadini 2009).

Chian 2000 also reported on this outcome, but results were not expressed per woman randomised, so could not be entered into the meta-analysis. The study authors reported no evidence of a difference in clinical pregnancy rates between the two groups (Table 1).

\subsection{Drug reactions}

No studies reported on this outcome.

\subsection{Adverse effects}

No studies reported on this outcome.

\subsection{Number of oocytes retrieved}

Three studies reported the number of oocytes retrieved. Fadini 2009 reported that the number of retrieved oocytes in participants receiving 10,000 units hCG priming was 495 (mean $5.3 \pm 4.1$ ) versus 494 (mean $5.3 \pm 4.2$ ) in participants receiving no priming. There was no evidence of a difference between the groups (mean difference (MD) $0.00,95 \% \mathrm{Cl}-1.15$ to $1.15 ; 1 \mathrm{RCT} ; \mathrm{N}=200$; low quality evidence; Analysis 1.4)

Zheng 2012 also found no evidence of a difference between groups for this outcome. The number of retrieved oocytes in participants receiving 10,000 units hCG priming was 552 (mean 13.8) versus 603 (mean 14.35) in participants with no priming. We were unable to calculate the mean difference as the standard deviations were not reported. The data from both these studies are presented in Table 2.
Chian 2000 also reported no evidence of a difference between the groups for this outcome, though these results were not expressed per woman randomised (Table 1 ).

\subsection{Mean percentage of mature oocytes at 0 hours as a proportion of oocytes retrieved}

No studies reported on this outcome.

\subsection{Mean percentage of oocytes at metaphase II after 24 hours as a proportion of oocytes retrieved}

No studies reported on this outcome.

\subsection{Mean percentage of oocytes at metaphase II after 48 hours as a} proportion of oocytes retrieved

The two studies that calculated maturation rates per woman randomised did not report this at 48 hours, and were not comparable enough to be pooled in a meta-analysis (Fadini 2009; Zheng 2012). Zheng 2012 found evidence of an improvement in the maturation rates of oocytes at 32 hours in the hCG primed group $(55.43 \%$ with 10,000 units hCG priming versus $42.29 \%$ with no priming; $\mathrm{P}=0.000$ ). Fadini 2009 reported on maturation rates at 30 hours (as a proportion of the total oocytes, but excluding degenerated oocytes that had been discarded). They found evidence of an improvement in maturation rates with hCG priming $(57.9 \%$ with 10,000 units $h C G$ priming versus $48.4 \%$ with no priming; $\mathrm{P}=0.002$ ). The data for both of these studies are presented in Table 2.

Chian 2000 also reported evidence of an improvement in maturation rates at 48 hours with $\mathrm{hCG}$ priming, though results were not expressed per woman randomised (Table 1). 
2.10 Mean percentage of oocytes fertilised as a proportion of mature oocytes available

Two studies reported on this outcome per woman randomised; neither found evidence of a difference between the groups with hCG priming. Zheng 2012 reported fertilisation rates of $63.4 \%$ with 10,000 units hCG priming versus $65.49 \%$ with no priming; $P=$ not significant. Fadini 2009 reported fertilisation rates of $71.5 \%$ with 10,000 units hCG priming versus $77.6 \%$ with no priming; $P=$ not significant. However, it should be noted that no more than three oocytes per cycle could be used in this study, according to Italian law. Therefore, the fertilisation rates were not calculated as the proportion of total mature oocytes available. The data for both studies are presented in Table 2.

The study authors in Chian 2000 did not find evidence of a difference between the groups for this outcome, though results were not expressed per woman randomised (Table 1).

\subsection{Mean percentage of embryos cleaved as a proportion of oocytes} fertilised

Zheng 2012 was the only study that reported on this outcome per woman randomised, and found no evidence of a difference between the groups (98.97\% with 10,000 units hCG priming versus 99.10\% with no priming; $P=$ not significant; Table 2 ).

Chian 2000, although not reporting results per woman randomised, also found no evidence of a difference between the groups for this outcome (Table 1 ).

\subsection{Mean percentage of embryos implanted as a proportion of} embryos transferred

Two studies reported on this outcome. Zheng 2012 reported no evidence of a difference in implantation rates $(32.86 \%$ with 10,000 units hCG priming versus $32.56 \%$ with no priming; $P=$ not significant). Fadini 2009 also reported no evidence of a difference between groups for this outcome (4.0\% with 10,000 units hCG priming versus $9.2 \%$ with no priming; $P=$ not significant). The results from these studies are presented in Table 2.

\section{Comparison of different doses of hCG}

Only one of the included studies reported on this intervention. Gulekli 2004 compared 20,000 units hCG priming versus 10,000 units hCG priming.

\section{Primary outcome}

\subsection{Live birth rate (defined as a live birth rate after 24 completed} weeks gestation)

This outcome was not reported.

\subsection{Miscarriage rate}

This outcome was not reported.

\section{Secondary outcomes:}

3.3 Clinical pregnancy rate (defined as the presence of a fetal heart on ultrasound after six weeks gestation)

There was no evidence of a difference between the groups in the number of clinical pregnancies, although the actual figures were not reported.

\subsection{Drug reactions}

This outcome was not reported.

\subsection{Adverse events}

This outcome was not reported.

\subsection{Number of oocytes retrieved}

There was no evidence of a difference between the groups in the mean number of immature oocytes retrieved (151 immature oocytes in the nine women treated with 20,000 units hCG priming and 180 immature oocytes in the 14 women treated with 10,000 units hCG priming; P value was not reported).

3.7 Mean percentage of mature oocytes at 0 hours as a proportion of oocytes retrieved

This outcome was not reported.

3.8 Mean percentage of oocytes at metaphase II after 24 hours as a proportion of oocytes retrieved

No evidence of a difference between the groups was seen in maturation rates at 24 hours with 20,000 units hCG compared to 10,000 units $\mathrm{hCG}(53.0 \%$ versus $56.7 \%$; $P=0.44)$.

3.9 Mean percentage of oocytes at metaphase II after 48 hours as a proportion of oocytes retrieved

No evidence of a difference between the groups was seen in maturation rates at 48 hours with 20,000 units hCG compared to 10,000 units hCG $(74.2 \%$ versus $70.5 \%$; $P=0.46)$.

3.10 Mean percentage of oocytes fertilised as a proportion of mature oocytes available

The study authors reported that fertilisation rates were significantly lower with 20,000 units hCG compared to 10,000 units (58.9\% versus $71.7 \% ; P=0.03)$.

3.11 Mean percentage of embryos cleaved as a proportion of oocytes fertilised

No evidence of a difference between the groups was seen in cleavage rate with 20,000 units hCG compared to 10,000 units (87.9\% versus $90.1 \% ; P=0.62$ ).

\subsection{Mean percentage of embryos implanted as a proportion of} embryos transferred

This outcome was not reported.

\section{Comparison of different timing of hCG}

No studies reported on this comparison

\section{DISCUSSION}

\section{Summary of main results}

This Cochrane review aimed to evaluate the effectiveness and safety of human chorionic gonadotrophin (hCG) priming in women who were undergoing in vitro maturation (IVM) treatment to achieve clinical pregnancy and live birth. We included four studies, with a total of 522 women. Three studies compared 10,000 units of hCG with no priming. One study compared different doses of hCG $(20,000$ units versus 10,000 units). Apart from one larger study, the number of women in the trials was generally small. 
For the comparison of 10,000 units hCG priming versus no priming, there was no evidence of a difference between the groups in live birth rate, miscarriage rate, or clinical pregnancy rate. However, findings for clinical pregnancy, though inconclusive, suggested that hCG may be associated with a reduction in pregnancy rates. No studies reported on drug reactions or adverse effects.

Only one study compared different doses of hCG priming $(20,000$ units versus 10,000 units (Gulekli 2004)). The live birth rate and miscarriage rate were not reported. No difference in the clinical pregnancy rate was found.

The quality of evidence from the included studies was low, the main limitations being lack of blinding and imprecision.

\section{Overall completeness and applicability of evidence}

One of the primary outcomes, live birth rate per woman randomised, was only reported in one study (Zheng 2012). For women, this is likely the most important result. Fadini 2009 did comment on total number of live births, but did not give numbers per treatment group. Our other primary outcome of miscarriage rate was reported in two of the studies (Fadini 2009; Zheng 2012).

In our protocol, we had stated that we would include two other comparisons, studies comparing hCG with placebo priming and studies comparing timing of hCG priming. However, we did not find any studies investigating these comparisons.

Only four studies had data relevant to the review question. The study populations were similar in age, with all women younger than 41 years. However, the type of subfertility varied. Three studies only included women with polycystic ovarian syndrome (PCOS), while in one study, this was an exclusion criterion (Fadini 2009). Fadini 2009 was the largest included study, and contributed significantly to our results. As IVM appears to be most suitable for women with PCOS, who are at increased risk of ovarian hyperstimulation syndrome (OHSS), some of our findings will be less applicable to this patient group. To overcome this, we performed subgroup analysis for the outcomes of miscarriage rate and clinical pregnancy rate. The outcome of live birth rate was only reported by Zheng 2012, which only included women with PCOS.

\section{Quality of the evidence}

The included trials varied in the quality of their methodology. All the included studies reported their method of randomisation and thus, were deemed at low risk of bias for this domain. No studies reported adequate allocation concealment or adequate participant blinding. In three studies, the comparator was no priming, although it would have been possible to use a placebo. Only one study reported on blinding of clinician and embryologist. The 'Risk of bias' assessments are summarised in Figure 1 and Figure 2.

We rated the quality of evidence using GRADE methods. Overall, the quality of the evidence was low. The main reasons for this were lack of blinding and imprecision.

\section{Potential biases in the review process}

We aimed to retrieve all eligible studies. However, there might have been some studies that were not yet published at the time of our search. Additional information was requested from some trial authors. We did not always receive a response, but our requests may not have reached the relevant person. We stated in our protocol that we would perform subgroup analyses, but due to insufficient data, these planned analyses were not performed. However, we did perform an additional subgroup analysis of PCOS status, which we had not originally planned in our protocol. Due to the small number of included studies, we were unable to construct a funnel plot, and so were not able to estimate possible publication bias.

\section{Agreements and disagreements with other studies or reviews}

We did not identify any other systematic reviews on this topic. However, a literature review has looked at the effects and timing of an hCG trigger (Reinblatt 2011). They reported on one of our included studies, which demonstrated an improvement in maturation rate when 10,000 units hCG priming was administered (Chian 2000). However, this was not reflected in higher pregnancy rates, and this review also reported on studies where good pregnancy rates were achieved without hCG. They concluded that using hCG alone to trigger maturation was beneficial in PCOS patients, but that this might not be the case in normoovulatory patients. This possible improvement in maturation rate was consistent with the trend reported in our present review. Here, an improvement was also seen in the study that only included women without PCOS (Fadini 2009). However, none of these results could be entered into the meta-analysis. Since the quality of the evidence was low, these results should be interpreted with caution.

The effect of timing between the hCG trigger and oocyte retrieval was investigated in a retrospective study that compared a postpriming wait of 35 hours and 38 hours before oocyte retrieval (Son 2008). The longer post-hCG interval resulted in a higher number of matured oocytes, but this was not reflected in a higher fertilisation or cleavage rate. They concluded that 38 hours appeared to maximise the chance to retrieve a mature follicle, but acknowledged that this had not been investigated in a randomised trial. Overall, the authors highlighted the need for further, well designed, prospective studies in order to establish the ideal method for oocyte priming and the timing of retrieval. This is in keeping with the conclusions of our present review.

\section{AUTHORS' CONCLUSIONS}

\section{Implications for practice}

This review found no conclusive evidence that human chorionic gonadotrophin (hCG) priming had an effect on live birth, pregnancy, or miscarriage rates in in vitro maturation (IVM). There was some low quality evidence to suggest that hCG priming may reduce clinical pregnancy rates. But, these findings were limited by the small number of data included. As no data were available on adverse events (other than miscarriage) or on drug reactions, the safety of hCG priming could not be adequately assessed. We need further evidence from well-designed RCTs before we can come to definitive conclusions about the role of hCG priming, and the optimal dose and timing.

\section{Implications for research}

Further larger randomised controlled trials using CONSORT standards are required (Moher 2010), initially investigating hCG priming versus placebo priming. The data should be measured per woman randomised, rather than per cycle, with thorough 
documentation of the methods used for allocation concealment and blinding. Live birth rate and adverse effects should be reported. In addition, as IVM is likely to be most appropriate for women with polycystic ovaries or PCOS, it would be best to investigate this cohort of women first. Other potential patient groups for whom IVM is applicable should also be considered, including women with ovarian resistance to gonadotrophins, previous high responders to ovarian stimulation, and women who require urgent fertility preservation prior to cancer treatment.

\section{ACKNOWLEDGEMENTS}

We are grateful for the assistance of the Cochrane Gynaecology and Fertility Group, especially Marian Showell, Information Specialist, for writing and running the search strings, and Helen Nagels, Managing Editor, for answering the additional questions we had. In addition, we thank the original authors of the papers who took time to respond to any queries. 


\section{R E F E R E N C E S}

\section{References to studies included in this review}

Chian 2000 \{published data only\}

Buckett W, Chian RC, Tan SL. Effects of HCG priming on ultrasound endometrial parameters and embryo implantation in an in-vitro maturation programme: a prospective randomized controlled trial. Human Reproduction 2003;18(suppl 1):139.

Buckett WM, Chian RC, Tan SL. A prospective randomized study of HCG priming prior to immature oocyte retrieval and in-vitro maturation of oocytes in unstimulated women with polycystic ovaries.. Human Reproduction 1999;14:27-8.

Buckett WM, Chian RC, Tan SL. Human chorionic gonadotropin for in vitro oocyte maturation: does it improve the endometrium or implantation?. The Journal of Reproductive Medicine 2004;49(2):93-8.

* Chian RC, Buckett WM, Tulandi T, Tan SL. Prospective randomized study of human chorionic gonadotrophin priming before immature oocyte retrieval from unstimulated women with polycystic ovarian syndrome. Human Reproduction 2000;15(1):165-70.

\section{Fadini 2009 \{published data only\}}

Fadini R, Dal Canto MB, Mignini Renzini M, Brambillasca F, Comi R, Fumagalli D, et al. Effect of different gonadotrophin priming on IVM of oocytes from women with normal ovaries: a prospective randomized study. Reproductive Biomedicine Online 2009;19(3):343-51.

\section{Gulekli 2004 \{published data only\}}

Gulekli B, Buckett WM, Chian RC, Child TJ, Abdul-Jalil AK, Tan SL. Randomized, controlled trial of priming with 10,000 IU versus 20,000 IU of human chorionic gonadotropin in women with polycystic ovary syndrome who are undergoing in vitro maturation.. Fertility \& Sterility 2004;82(5):1458-9.

\section{Zheng 2012 \{published data only\}}

* Zheng X, Wang L, Zhen X, Lian Y, Liu P, Qiao J. Effect of hCG priming on embryonic development of immature oocytes collected from unstimulated women with polycystic ovarian syndrome.. Reproductive Biology and Endocrinology 2012;10(1):40.

Zheng XY, Wang LN, Liu P, Qiao J. Effect of HCG priming on embryonic development of immature oocytes collected from unstimulated women with polycystic ovarian syndrome: a controlled randomized study. Human Reproduction 2011;26(suppl 1):i192; P-177. [DOI: 10.1093/humrep/26.s1.79]

\section{References to studies excluded from this review}

\section{Chian 2001 \{published data only\}}

Chian R, Tan S, Casper R. Immature oocyte retrieval and in vitro maturation in women with polycystic ovaries at $36 \mathrm{~h}$ or $40 \mathrm{~h}$ after the administration of HCG. Fertility \& Sterility 2001; Vol. 76 , issue 3 Suppl 1:S227.
Kim 2013 \{published data only\}

Kim MK, Park EA, Kim HJ, Choi WY, Cho JH, Lee WS, et al. Does supplementation of in-vitro culture medium with melatonin improve IVF outcome in PCOS?. Reproductive Biomedicine Online 2013; Vol. 26, issue 1:22-9.

\section{Son 2001 \{published data only\}}

Son W, Yoon S, Hyun C, Lee S, Lee W, Lin J. Effect of in-vivo HMG or HCG stimulation on IVM/F-embryo transfer outcome of oocytes collected from women with OHSS experience.. Human Reproduction 2001; Vol. 16, issue suppl 1:75-6.

\section{References to ongoing studies \\ ISRCTN17078060 \{published data only\}}

ISRCTN17078060. In vitro maturation as part of the treatment of infertility in women with polycystic ovaries. Is priming with hCG favourable? A prospective randomized study. available from www.isrctn.com/ISRCTN17078060. [DOI: 10.1186/ ISRCTN17078060]

\section{Additional references}

\section{Al-Inany 2011}

Al-Inany HG, Youssef MA, Aboulghar M, Broekmans F, Sterrenburg M, Smit J, et al. GnRH antagonists are safer than agonists: an update of a Cochrane review. Human Reproduction Update 2011;17:435.

\section{Al-Shawaf 2001}

Al-Shawaf T, Zosmer A, Hussain S, Tozer A, Panay N, Wilson C, et al. Prevention of severe ovarian hyperstimulation syndrome in IVF with or without ICSI and embryo transfer: a modified "coasting" strategy based on ultrasound for identification of high-risk patients. Human Reproduction 2001;16:24-30.

\section{Cha 1998}

Cha KY, Chian RC. Maturation in vitro of immature human oocytes for clinical use. Human Reproduction Update 1998;4(2):103-20.

\section{Child 2001}

Child TJ, Abdul Jalil AK, Guleki B, Tan SL. In vitro maturation of oocytes from unstimulated normal ovaries, polycystic ovaries, and women with polycystic ovarian syndrome. Fertility and Sterility 2001;76(5):936-42.

\section{Child 2002}

Child TJ, Abdul-Jalil AK, Gulakli B, Tan SL. A comparison of in vitro maturation and in vitro fertilization for women with polycystic ovaries. Obstetrics and Gynaecology 2002;100(4):665-70.

\section{Delvigne 2002}

Delvigne A, Roenberg S. Systematic review of data concerning etiopathology of ovarian hyperstimulation syndrome. International Journal of Women's Medicine 2002;47(5):211-26. 


\section{GRADEpro GDT 2015 [Computer program]}

GRADE Working Group, McMaster University. GRADEpro GDT. Version accessed 14 February 2016. Hamilton (ON): GRADE Working Group, McMaster University, 2015.

\section{Higgins 2011}

Higgins JPT, Green S (editors). Cochrane Handbook for Systematic Reviews of Interventions Version 5.1.0 (updated March 2011). The Cochrane Collaboration, 2011. Available from handbook.cochrane.org.

\section{Moher 2010}

Moher D, Hopewell S, Schulz KF, Montori V, Gøtzsche PC, Devereaux PF, et al. CONSORT 2010 Explanation and Elaboration: updated guidelines for reporting parallel group randomised trials. Journal of Clinical Epidemiology 2010;63(8):e1-37.

\section{NICE 2013}

National Institute for Health and Care Excellence. Fertility: assessment and treatment for people with fertility problems. Clinical Guideline 156. Available from www.nice.org.uk/ Guidance/CG156 February 2013; Vol. updated August 2016.

\section{Reinblatt 2011}

Reinblatt SL, Son W, Shalom-Paz E, Holzer H. Controversies in IVM. Journal of Assisted Reproduction and Genetics 2011;28:525-30.

\section{RevMan 2014 [Computer program]}

Nordic Cochrane Centre, The Cochrane Collaboration. Review Manager (RevMan). Version 5.3. Copenhagen: Nordic Cochrane Centre, The Cochrane Collaboration, 2014.

\section{Rotterdam 2003}

Rotterdam ESHRE/ASRM-Sponsored PCOS Consensus Workshop Group. Revised 2003 consensus on diagnostic criteria and long term health risks related to polycystic ovary syndrome. Fertility and Sterility 2004;81:19-25.

\section{Siristatidis 2015}

Siristatidis C, Sergentanis T, Vogiatzi P, Kanavidis P, Chrelias C, Papantoniou $\mathrm{N}$, et al. In vitro maturation in women with vs. without polycystic ovarian syndrome: a systematic review and meta-analysis. PloS One 2015;10(8):e0134696. [DOI: 10.1371/ journal.pone.0134696]

\section{CHARACTERISTICS OF STUDIES}

Characteristics of included studies [ordered by study ID]

\section{Son 2005}

Son WY, Yoon SH, Lim JH. Effect of gonadotrophin priming in in-vitro maturation of oocytes collected from women at risk of OHSS. Reproductive Biomedicine Online 2006;13:340-8.

\section{Son 2008}

Son W, Chung J, Chian R, Herrero B, Demirtas E, Elizur S, et al. A $38 \mathrm{~h}$ interval between hCG priming and oocyte retrieval increases in vivo and in vitro oocyte maturation rate in programmed IVM cycles. Human Reproduction 2008;23(9):2010-6.

\section{Stuck 1998}

Stuck AE, Rubenstein LZ, Wieland D. Bias in meta-analysis detected by a simple graphical test. Asymmetry detected in funnel plot was probably due to true heterogeneity. BMJ 1998;316(7129):469; author reply 470-1. [Comment on: Bias in meta-analysis detected by a simple, graphical test. (BMJ. 1997)]

\section{Swanton 2010}

Swanton A, Storey L, McVeigh E, Child T. IVF outcome in women with PCOS, PCO and normal ovarian morphology. European Journal of Obstetrics, Gynaecology and Reproductive biology 2010;149(1):68-71.

\section{Tan 2002}

Tan SL, Child TJ, Gulekli B. In vitro maturation and fertilization of oocytes from unstimulated ovaries: predicting the number of immature oocytes retrieved by early follicular phase ultrasound. American Journal of Obstetrics and Gynecology 2002;186(4):684-9.

\section{Trounson 1994}

Trounson A, Wood C, Kausche A. in vitro maturation and the fertilization and developmental competence of oocytes recovered from untreated polycystic ovarian patients. Fertility and Sterility 1994;62(2):353-62.

\section{Yang 2005}

Yang SH, Son WY, Yoon SH, Ko Y, Lim JH. Correlation between in vitro maturation and expression of $\mathrm{LH}$ receptor in cumulus cells of the oocytes collected from PCOS patients in HCG-primed IVM cycles. Human Reproduction 2005;20:2097-103.

* Indicates the major publication for the study

Chian 2000

\begin{tabular}{ll} 
Methods & Prospective, randomised study \\
& 17 women underwent 24 completed treatment cycles \\
\hline Participants & $\begin{array}{l}\text { Women with PCOS who had failed to conceive after at least } 6 \text { cycles of ovulation induction undergoing } \\
\text { IVM. All patients were younger than } 41 \text { years and had a minimum 2-year history of infertility. }\end{array}$
\end{tabular}


Chian 2000 (Continued)

Interventions $\quad 10,000$ units hCG priming 36 hours prior to immature oocyte retrieval or no priming

\begin{tabular}{|c|c|c|}
\hline \multirow[t]{7}{*}{ Outcomes } & \multicolumn{2}{|c|}{ No. of oocytes retrieved } \\
\hline & \multicolumn{2}{|c|}{ No. of oocytes matured at 48 hours } \\
\hline & \multicolumn{2}{|c|}{ No. of oocytes fertilised } \\
\hline & \multicolumn{2}{|l|}{ No. of oocytes cleaved } \\
\hline & \multicolumn{2}{|c|}{ No. of embryos transferred } \\
\hline & \multicolumn{2}{|l|}{ Clinical pregnancy rate } \\
\hline & \multicolumn{2}{|l|}{ No. of miscarriages } \\
\hline Notes & \multicolumn{2}{|c|}{ Author contacted and responded. Per woman data not available. } \\
\hline \multicolumn{3}{|l|}{ Risk of bias } \\
\hline Bias & Authors' judgement & Support for judgement \\
\hline $\begin{array}{l}\text { Random sequence genera- } \\
\text { tion (selection bias) }\end{array}$ & Low risk & Treatment was allocated using a "computerised random table". \\
\hline $\begin{array}{l}\text { Allocation concealment } \\
\text { (selection bias) }\end{array}$ & Unclear risk & Not reported. \\
\hline $\begin{array}{l}\text { Blinding of participants } \\
\text { and personnel (perfor- } \\
\text { mance bias) } \\
\text { All outcomes }\end{array}$ & High risk & $\begin{array}{l}\text { No placebo used, therefore, it is clear that participants would not have been } \\
\text { blinded. }\end{array}$ \\
\hline $\begin{array}{l}\text { Blinding of outcome as- } \\
\text { sessment (detection bias) } \\
\text { All outcomes }\end{array}$ & Unclear risk & Not reported. \\
\hline $\begin{array}{l}\text { Incomplete outcome data } \\
\text { (attrition bias) } \\
\text { All outcomes }\end{array}$ & Unclear risk & Not reported. \\
\hline $\begin{array}{l}\text { Selective reporting (re- } \\
\text { porting bias) }\end{array}$ & Unclear risk & Study protocol not available to check whether outcomes were prespecified \\
\hline Other bias & Unclear risk & Insufficient information to detect other sources of bias. \\
\hline
\end{tabular}

\section{Fadini 2009}

Methods Prospective, randomised study

400 women were randomly allocated into 4 equal groups

Participants Women with an indication for IVF or ICSI because of infertility due to male factor, tubal factor, stage I/I endometriosis or unexplained infertility. Women with PCOS or PCO were excluded.

"The inclusion criteria were: age 24 to 38 years; normal ovulatory cycles with a mean length of 24 to 35 days; early follicular FSH concentration of less than $12 \mathrm{mIU} / \mathrm{mL}$; body mass index from 13 to $31 \mathrm{~kg} / \mathrm{m}^{2}$; and one or no previous cycles of conventional IVF and/or IVM without conceiving." 
Fadini 2009 (Continued)

All women with endocrine abnormalities, an ovarian cyst $\geq 12 \mathrm{~mm}$ or basal oestradiol concentrations > $75 \mathrm{pg} / \mathrm{L}$ were excluded.

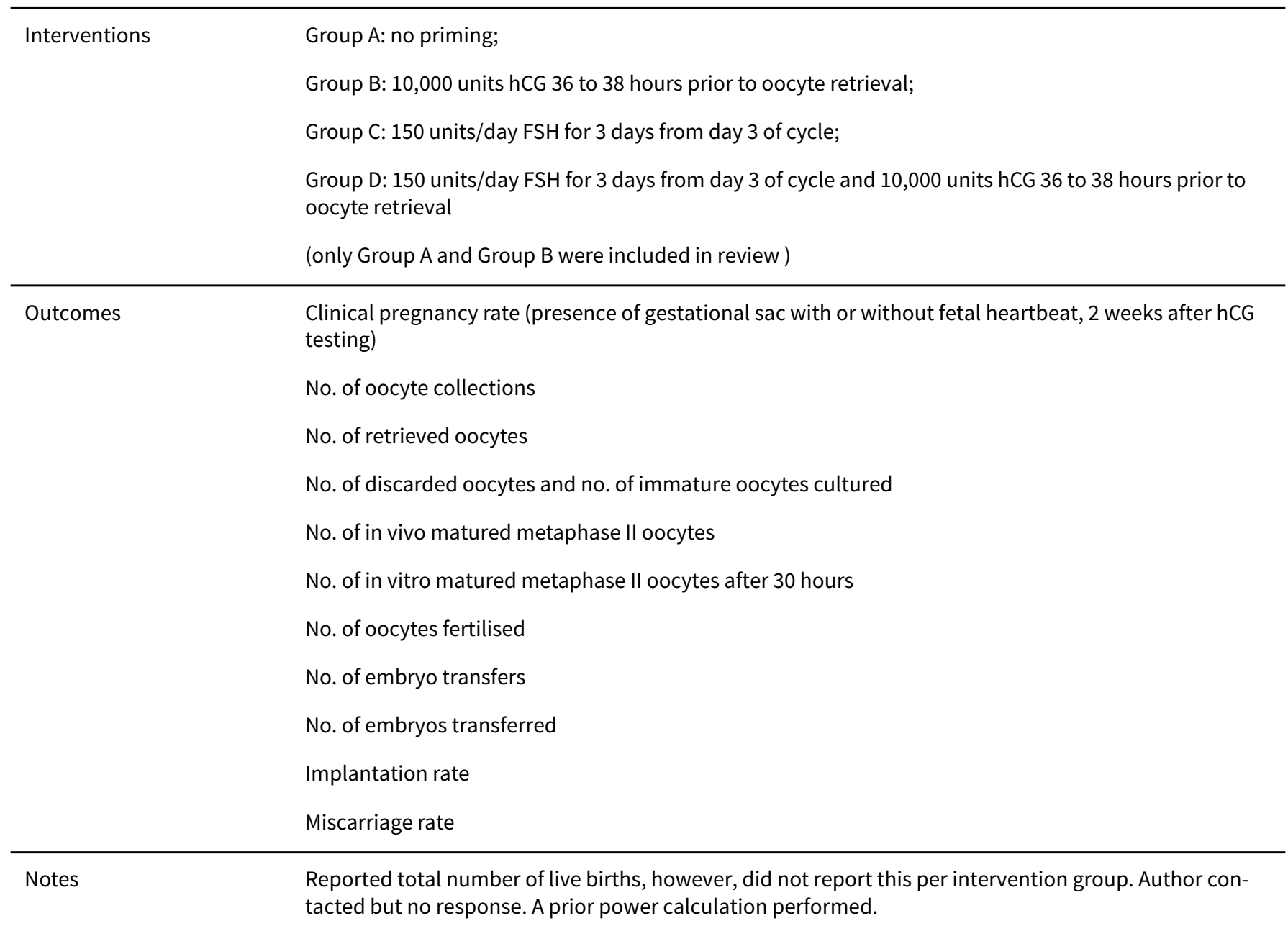

\section{Risk of bias}

\begin{tabular}{lll}
\hline Bias & Authors' judgement & Support for judgement \\
\hline $\begin{array}{l}\text { Random sequence genera- } \\
\text { tion (selection bias) }\end{array}$ & Low risk & Treatment allocated using a "computerised random table". \\
\hline $\begin{array}{l}\text { Allocation concealment } \\
\text { (selection bias) }\end{array}$ & Unclear risk & Not reported. \\
\hline $\begin{array}{l}\text { Blinding of participants } \\
\text { and personnel (perfor- } \\
\text { mance bias) }\end{array}$ & High risk & No placebo used therefore participants would not have been blinded. \\
All outcomes & \\
\hline $\begin{array}{l}\text { Blinding of outcome as- } \\
\text { sessment (detection bias) } \\
\text { All outcomes }\end{array}$ & Unclear risk & Not reported. \\
\hline $\begin{array}{l}\text { Incomplete outcome data } \\
\text { (attrition bias) } \\
\text { All outcomes }\end{array}$ & Low risk & \\
\hline
\end{tabular}


Fadini 2009 (Continued)

Selective reporting (re- Unclear risk Study protocol not available to check whether outcomes were prespecified. porting bias)

Other bias Unclear risk Insufficient information to detect other sources of bias.

\section{Gulekli 2004}

\begin{tabular}{ll}
\hline Methods & Randomised controlled trial \\
& 23 women were randomised into 2 groups $(10,000$ units hCG priming $(\mathrm{N}=14)$ and 20,000 units hCG \\
priming $(\mathrm{N}=9))$
\end{tabular}

\begin{tabular}{ll}
\hline Participants & $\begin{array}{l}\text { All women had a clinical diagnosis of PCOS and were aged < } 40 \text { years. They had a minimum 2-year his- } \\
\text { tory of infertility and had failed to conceive after at least six previous cycles of ovulation induction with } \\
\text { clomiphene citrate or gonadotrophins, with or without Intrauterine insemination. }\end{array}$
\end{tabular}

\begin{tabular}{ll}
\hline Interventions & 10,000 units or 20,000 units hCG priming 36 hours prior to immature oocyte retrieval \\
\hline Outcomes & Primary outcome: \\
& Oocyte maturation rate 24 and 48 hours after immature oocyte retrieval \\
& Secondary outcomes: \\
& Fertilisation and cleavage rates \\
\hline Notes & $\begin{array}{l}\text { Power calculations were performed. Author contacted and responded but original data no longer avail- } \\
\text { able. }\end{array}$ \\
\hline
\end{tabular}

\section{Risk of bias}

\begin{tabular}{lll}
\hline Bias & Authors' judgement & Support for judgement \\
\hline $\begin{array}{l}\text { Random sequence genera- } \\
\text { tion (selection bias) }\end{array}$ & Low risk & Treatment allocated "according to a computerised randomised table". \\
\hline $\begin{array}{l}\text { Allocation concealment } \\
\text { (selection bias) }\end{array}$ & Unclear risk & $\begin{array}{l}\text { "The numbers were kept in sealed envelopes and only opened once the deci- } \\
\text { sion to progress to immature oocyte retrieval was made. The envelopes were } \\
\text { stored and opened by an independent coordinator". However, it is unclear if } \\
\text { envelopes were opaque. }\end{array}$ \\
\hline
\end{tabular}

Blinding of participants Unclear risk No comment made on whether participants were blinded to the dose used.
and personnel (performance bias)

All outcomes

\begin{tabular}{|c|c|c|}
\hline $\begin{array}{l}\text { Blinding of outcome as- } \\
\text { sessment (detection bias) }\end{array}$ & Low risk & $\begin{array}{l}\text { "The clinician performing the immature oocyte retrieval and the embryologist } \\
\text { in the laboratory were unaware of the dose used." }\end{array}$ \\
\hline
\end{tabular}

All outcomes

Withdrawal not reported.

Incomplete outcome data Unclear risk Withdrawal not reported.
(attrition bias)
All outcomes
Selective reporting (re- Unclear risk Study protocol not available to check whether outcomes were prespecified. porting bias)


Gulekli 2004 (Continued)

Other bias Unclear risk Insufficient information to detect other sources of bias.

Zheng 2012

\begin{tabular}{ll} 
Methods & Randomised controlled study \\
& $\begin{array}{l}82 \text { women who were undergoing IVM cycles were randomised to } 10,000 \text { units hCG priming ( } N=40) \text { or no } \\
\text { priming }(\mathrm{N}=42)\end{array}$ \\
\hline Participants & $\begin{array}{l}\text { The participants all met the Rotterdam criteria for the diagnosis of polycystic ovarian syndrome. The } \\
\text { age of the women ranged from } 24 \text { to } 39 \text { years; mean } 30.2 \text { years). "Basic patient characteristics, includ- } \\
\text { ing mean female age, body mass index (BMI), and baseline FSH did not differ between the hCG primed } \\
\text { (40 women) and the non-primed (42 women) groups." }\end{array}$
\end{tabular}

Interventions

10,000 units hCG priming 36 to 38 hours prior to oocyte collection or no priming

\begin{tabular}{|c|c|c|}
\hline \multirow[t]{11}{*}{ Outcomes } & \multicolumn{2}{|l|}{ No. of oocytes retrieved } \\
\hline & \multicolumn{2}{|c|}{ Oocyte maturation rate at 32 hours } \\
\hline & \multicolumn{2}{|l|}{ No. of oocytes fertilised } \\
\hline & \multicolumn{2}{|l|}{ No. of oocytes cleaved } \\
\hline & \multicolumn{2}{|c|}{ Cycles with embryo transfer } \\
\hline & \multicolumn{2}{|c|}{ No. of embryos transferred } \\
\hline & \multicolumn{2}{|l|}{ Implantation rate } \\
\hline & \multicolumn{2}{|c|}{$\begin{array}{l}\text { Clinical pregnancy rate (presence of an intrauterine gestational sac on ultrasound on day } 35 \text { after em- } \\
\text { bryo transfer) }\end{array}$} \\
\hline & \multicolumn{2}{|l|}{ Live birth rate } \\
\hline & \multicolumn{2}{|c|}{ Miscarriage rate (pregnancy loss after ultrasonographic evidence of an intrauterine pregnancy) } \\
\hline & \multicolumn{2}{|c|}{ No. of cycles with embryo freezing } \\
\hline Notes & \multicolumn{2}{|c|}{$\begin{array}{l}\text { Funded by National Science Fund for Distinguished Young Scholars and State Basic Research Develop- } \\
\text { ment Program of China. No competing interests declared. Author contacted but no response. }\end{array}$} \\
\hline \multicolumn{3}{|l|}{ Risk of bias } \\
\hline Bias & Authors' judgement & Support for judgement \\
\hline $\begin{array}{l}\text { Random sequence genera- } \\
\text { tion (selection bias) }\end{array}$ & Low risk & Treatment allocated using a "computerised random table" \\
\hline $\begin{array}{l}\text { Allocation concealment } \\
\text { (selection bias) }\end{array}$ & Unclear risk & Not reported. \\
\hline $\begin{array}{l}\text { Blinding of participants } \\
\text { and personnel (perfor- } \\
\text { mance bias) } \\
\text { All outcomes }\end{array}$ & High risk & $\begin{array}{l}\text { " The patients and the embryologist were blind to the randomised results." } \\
\text { Comment: Patients unable to be blinded as were either receiving hCG priming } \\
\text { by subcutaneous injection followed by oocyte collection } 36 \text { to } 38 \text { hours post } \\
\text { priming or no hCG injection and immediate oocyte collection. There was no } \\
\text { placebo used. }\end{array}$ \\
\hline
\end{tabular}


Zheng 2012 (Continued)
Blinding of outcome as-
Unclear risk
Embryologist "blind to the random results" sessment (detection bias)
All outcomes
Comment: No explanation as to how the embryologists were blinded. No com- ment on blinding of other assessors e.g. sonographers, clinicians

\begin{tabular}{lll}
\hline $\begin{array}{l}\text { Incomplete outcome data } \\
\text { (attrition bias) } \\
\text { All outcomes }\end{array}$ & Unclear risk & Withdrawals not reported. \\
\hline $\begin{array}{l}\text { Selective reporting (re- } \\
\text { porting bias) }\end{array}$ & Unclear risk & Study protocol not available to check whether outcomes were prespecified \\
\hline Other bias & Low risk & $\begin{array}{l}\text { Funding stated and no competing interests declared. No significant difference } \\
\text { reported in basic patient characteristics between the two groups. }\end{array}$
\end{tabular}

PCOS = polycystic ovarian syndrome

IVM = in vitro maturation

hCG = human chorionic gonadotrophin

IVF = in vitro fertilisation

ICSI = intracytoplasmic sperm injection

$\mathrm{PCO}=$ polycystic ovaries

$\mathrm{FSH}=$ follicle stimulating hormone

Characteristics of excluded studies [ordered by study ID]

\begin{tabular}{ll}
\hline Study & Reason for exclusion \\
\hline Chian 2001 & Not a randomised controlled trial. \\
\hline Kim 2013 & Not a randomised controlled trial. \\
\hline Son 2001 & Not a randomised controlled trial. \\
\hline
\end{tabular}

Characteristics of ongoing studies [ordered by study ID]

\section{ISRCTN17078060}

Trial name or title In vitro maturation as part of the treatment of infertility in women with polycystic ovaries. Is priming with hCG favourable? A prospective randomized study.

\begin{tabular}{ll}
\hline Methods & Prospective open label randomised controlled trial. \\
\hline Participants & $\begin{array}{l}\text { 1. Women with polycystic ovaries (PCO) according to Rotterdam criteria (2003) } \\
\text { 2. Referred to the Fertility Clinic, Odense University Hospital } \\
\text { 3. Candidates for IVF-treatment according to the standards of the Fertility Clinic }\end{array}$ \\
\hline Interventions & hCG injection vs no injection 36 hours before aspiration of oocytes \\
\hline Outcomes & Primary outcomes: \\
& $\begin{array}{l}\text { 1. Maturation rate (number of mature oocytes per number of aspirated oocytes) at } 30 \text { and } 46 \text { hours } \\
\text { 2. Fertilization rate (number of fertilized oocytes per number of matured oocytes) at } 46 \text { and } 70 \text { hours } \\
\text { Secondary outcomes: }\end{array}$
\end{tabular}


ISRCTN17078060 (Continued)

1. Number of transferable embryos with normal development on day 2 after fertilization, as a fraction of aspirated, matured and fertilized oocytes in IVF and Intra Cytoplasmatic Sperm Injection (ICSI) groups

2. Maturation rate in relation to follicle size (46 hours after maturation)

3. Maturation rate in relation to serum concentrations of various hormones, measured on various cycle days and days of randomisation and aspiration

\begin{tabular}{ll}
\hline Starting date & 01 April 2006 \\
\hline Contact information & Department of Obstetrics and Gynaecology \\
& Odense University Hospital \\
& Soendre Boulevard 29 \\
& Odense C \\
5000 \\
Denmark \\
+456541572
\end{tabular}

DATA AND ANALYSES

Comparison 1. 10,000 units hCG priming versus no priming

\begin{tabular}{lllll}
\hline $\begin{array}{l}\text { Outcome or subgroup ti- } \\
\text { tle }\end{array}$ & No. of studies & $\begin{array}{l}\text { No. of partici- } \\
\text { pants }\end{array}$ & Statistical method & Effect size \\
\hline 1 Live birth rate & 1 & 82 & Odds Ratio (M-H, Fixed, 95\% Cl) & $0.65[0.24,1.74]$ \\
\hline 1.1 Women with PCOS & 1 & 82 & Odds Ratio (M-H, Fixed, 95\% Cl) & $0.65[0.24,1.74]$ \\
\hline 2 Miscarriage rate & 2 & 282 & Odds Ratio (M-H, Fixed, 95\% Cl) & $0.60[0.21,1.72]$ \\
\hline 2.1 Women with PCOS & 1 & 82 & Odds Ratio (M-H, Fixed, 95\% Cl) & $0.75[0.24,2.39]$ \\
\hline 2.2 Women without PCOS & 1 & 200 & Odds Ratio (M-H, Fixed, 95\% Cl) & $0.20[0.01,4.14]$ \\
\hline 3 Clinical pregnancy rate & 2 & 282 & Odds Ratio (M-H, Fixed, 95\% Cl) & $0.52[0.26,1.03]$ \\
\hline 3.1 Women with PCOS & 1 & 82 & Odds Ratio (M-H, Fixed, 95\% Cl) & $0.6[0.25,1.45]$ \\
\hline 3.2 Women without PCOS & 1 & 200 & Odds Ratio (M-H, Fixed, 95\% Cl) & $0.43[0.14,1.27]$ \\
\hline $\begin{array}{l}4 \text { Number of oocytes re- } \\
\text { trieved }\end{array}$ & 1 & 200 & Mean Difference (IV, Fixed, 95\% Cl) & $0.0[-1.15,1.15]$ \\
\hline
\end{tabular}


Analysis 1.1. Comparison 1 10,000 units hCG priming versus no priming, Outcome 1 Live birth rate.

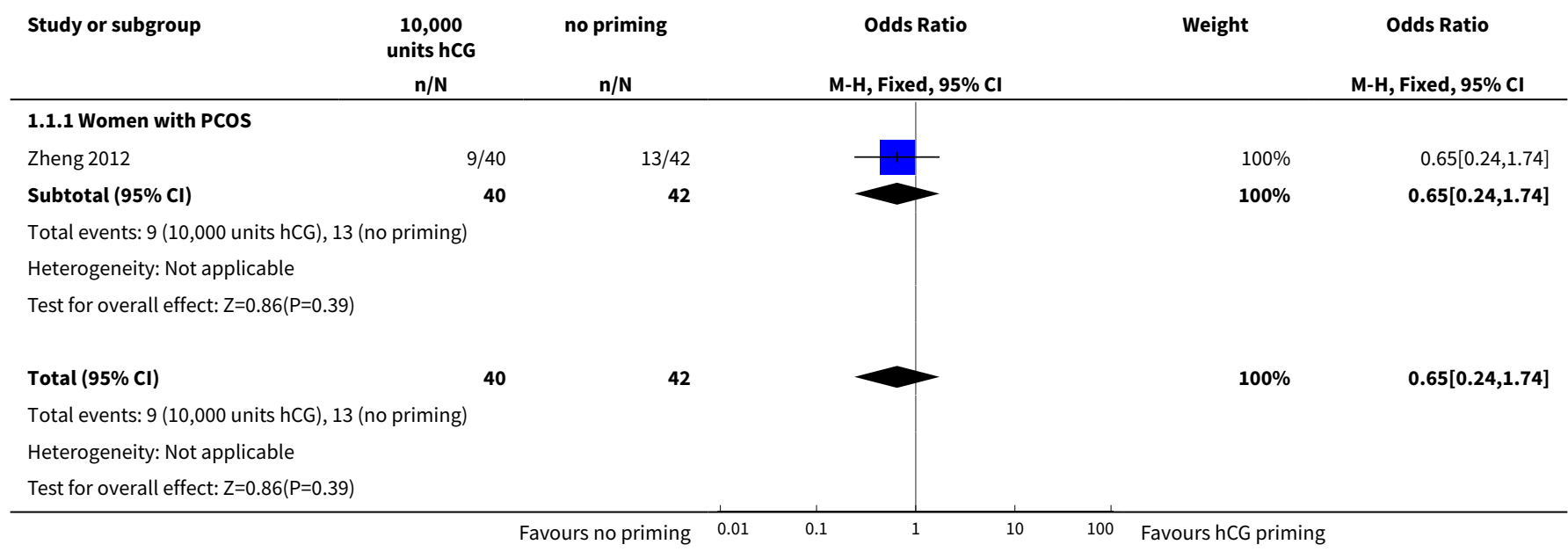

Analysis 1.2. Comparison 1 10,000 units hCG priming versus no priming, Outcome 2 Miscarriage rate.

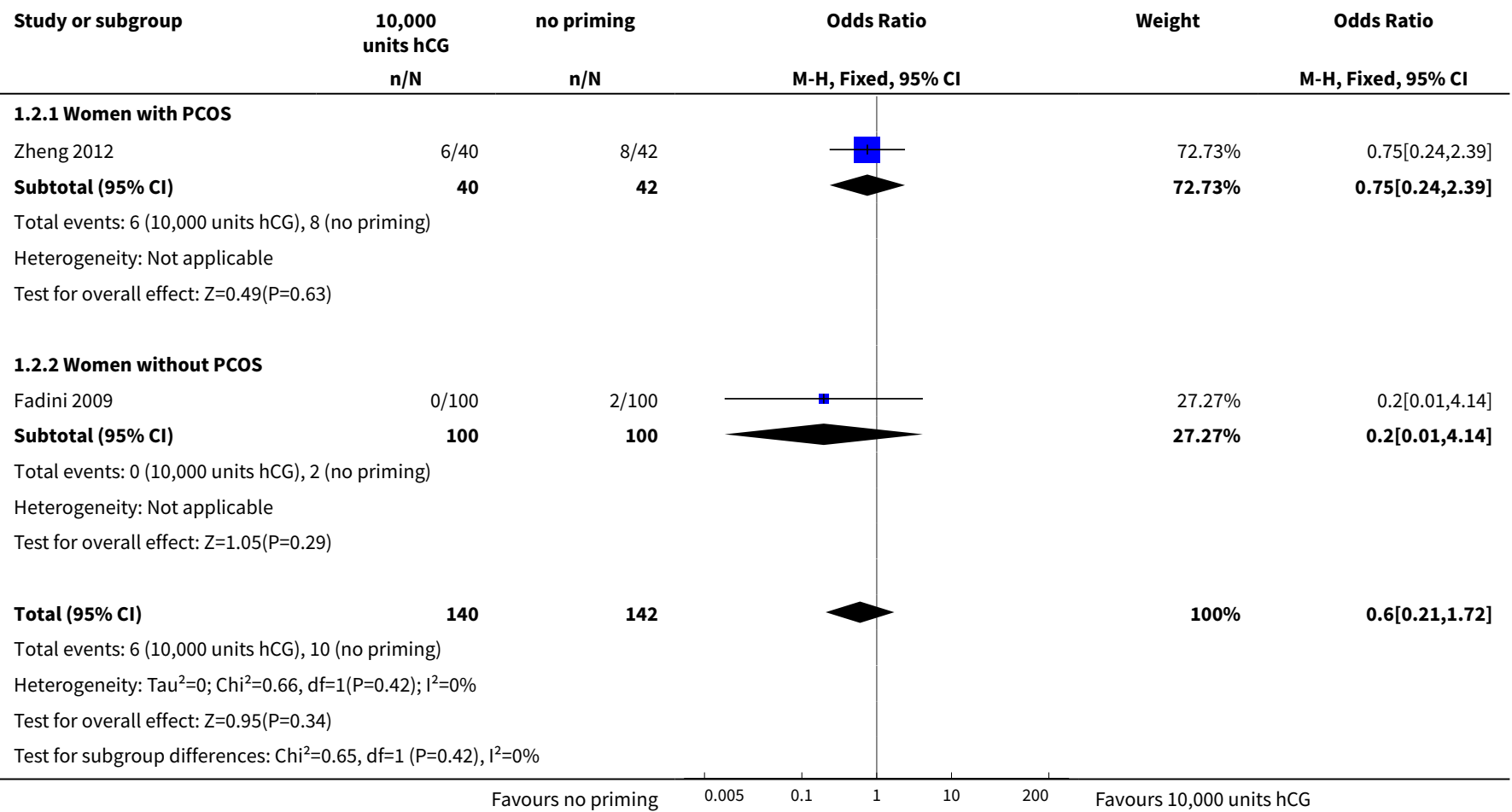

Analysis 1.3. Comparison 110,000 units hCG priming versus no priming, Outcome 3 Clinical pregnancy rate.

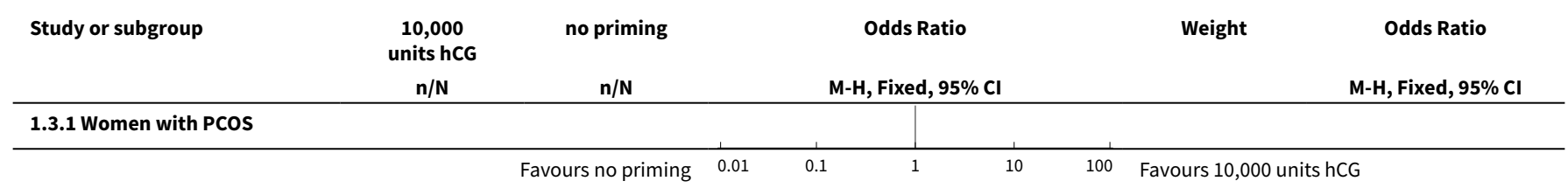




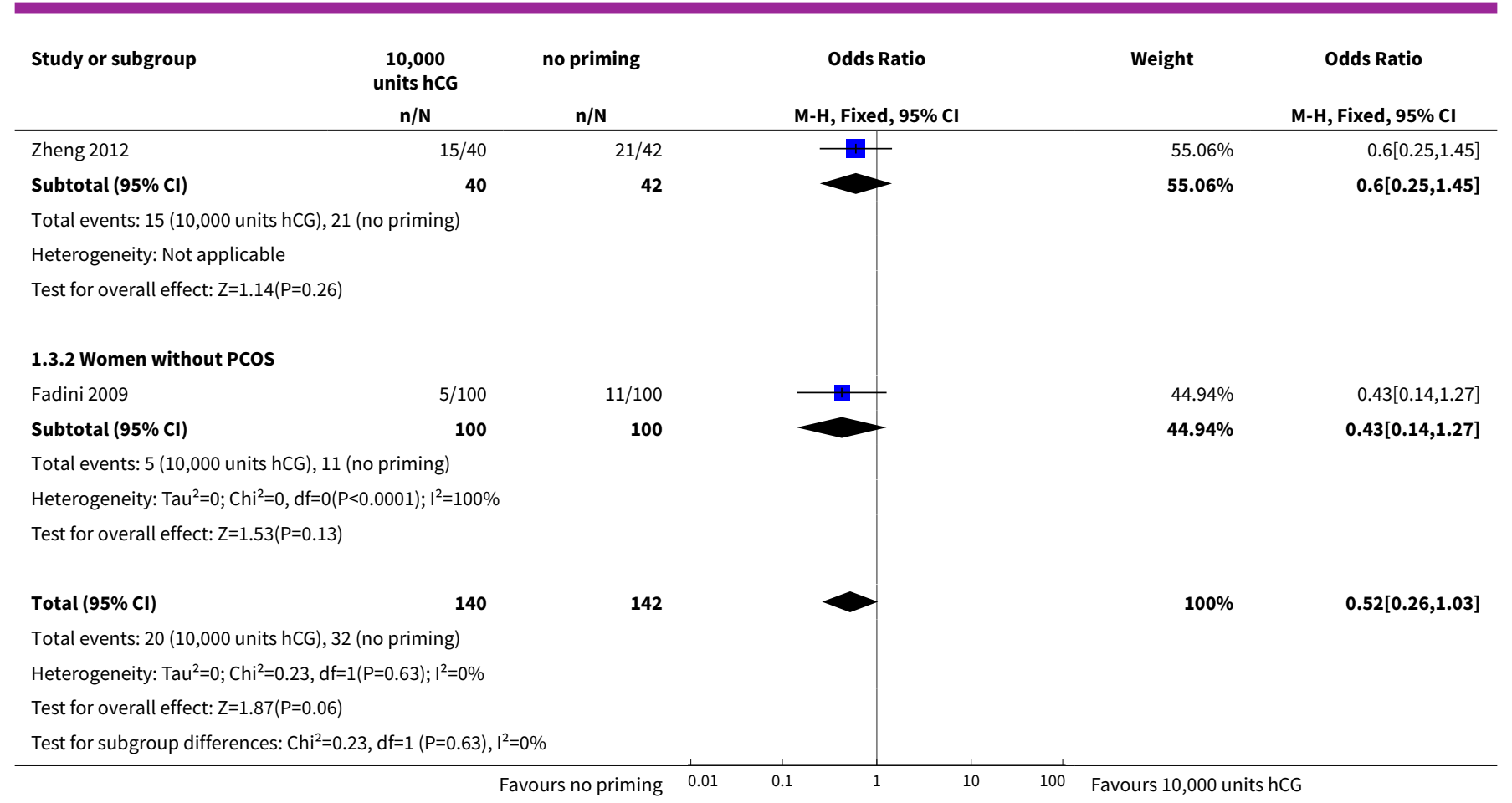

Analysis 1.4. Comparison 1 10,000 units hCG priming versus no priming, Outcome 4 Number of oocytes retrieved.

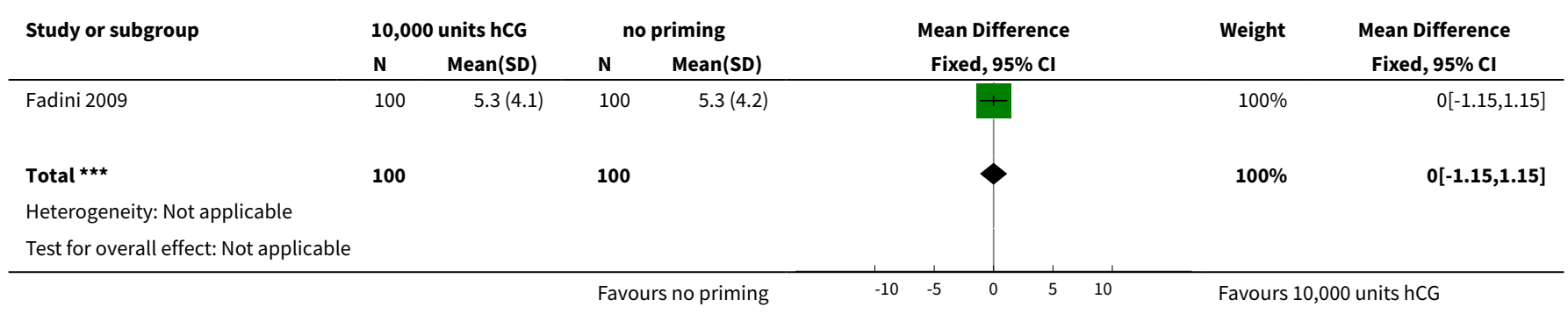

\section{ADDITIONAL TABLES}

Table 1. Data from Chian 2000 study

\section{Chian 2000}

\begin{tabular}{llll}
\hline & no priming & $\mathbf{1 0 , 0 0 0 ~ u n i t s ~ h C G ~}$ \\
\hline Cycles & 11 & 13 & $102(7.8 \pm 3.9)$ \\
\hline No. of retrieved oocytes (mean \pm SE) & $81(7.4 \pm 5.2)$ & $86(84.3)$ & $\mathrm{ns}<0.05$ \\
\hline No. of oocytes matured at 48 hours (\%) & $56(69.1)$ & $78(90.7)$ & $\mathrm{ns}$ \\
\hline No of oocytes fertilised $(\%)$ & $47(83.9)$ & \\
\hline
\end{tabular}


Table 1. Data from Chian 2000 study (Continued)

\begin{tabular}{llcl} 
No. of oocytes cleaved (\%) & $45(95.7)$ & $74(94.9)$ & ns \\
\hline No. of embryos transferred (mean \pm SE) & $27(2.5 \pm 1.1)$ & $36(2.8 \pm 0.9)$ & ns \\
\hline No. of clinical pregnancies (\%) & $3(27.3)$ & $5(38.5)$ & ns \\
\hline
\end{tabular}

Data from study in which results were not expressed per woman randomised ns = non significant

Table 2. Additional outcomes from Fadini 2009 and Zheng 2012 studies

\begin{tabular}{|c|c|c|c|c|c|c|}
\hline & \multicolumn{3}{|l|}{ Fadini 2009} & \multicolumn{3}{|l|}{ Zheng 2012} \\
\hline & no priming & $\begin{array}{l}10,000 \text { units } \\
\text { hCG }\end{array}$ & & no priming & $\begin{array}{l}10,000 \text { units } \\
\text { hCG }\end{array}$ & \\
\hline No. of oocyte retrieval cycles & 93 & 93 & & 42 & 40 & \\
\hline No. of oocytes retrieved & $494(5.3 \pm 4.2)$ & $495(5.3 \pm 4.1)$ & ns & $603(14.35)^{a}$ & $552(13.80)^{a}$ & ns \\
\hline \multicolumn{7}{|l|}{ Total (mean \pm SD) } \\
\hline No. of mature oocytes (\%) & $231 / 477(48.4)^{b}$ & $256 / 442(57.9)^{b}$ & ns & $255(42.29)^{c}$ & $306(55.43) c$ & $P=0.00$ \\
\hline No. of oocytes fertilised (\%) & $142 / 183(77.6)$ & $138 / 193(71.5)$ & ns & $167(65.49)$ & $194(63.40)$ & ns \\
\hline No. of oocytes cleaved (\%) & not reported & not reported & & $166(99.10)$ & $192(98.97)$ & ns \\
\hline No. of embryos implanted (\%) & $12 / 130(9.2)$ & $5 / 125(4.0)$ & ns & $28(32.56)$ & $23(32.86)$ & ns \\
\hline
\end{tabular}

Outcome data that was unable to be pooled for meta-analysis

ns = non significant

$a=$ No standard deviation (SD) reported for this study outcome

$\mathrm{b}=$ after 30 hours

$c=$ after 32 hours

\section{AP PE N DICES}

\section{Appendix 1. Search Strategy}

\section{Gynaecology and Fertility Group Specialised register (Procite database)}

from inception until 12 January 2016

Keywords CONTAINS "in vitro maturation"or"in vivo maturation"or "oocyte maturation" or "oocyte activation" or "oocyte preparation techniques" or "oocyte incubation" or "IVM" or "priming" or Title CONTAINS "in vitro maturation"or"in vivo maturation"or "oocyte maturation" or "oocyte activation" or "oocyte preparation techniques" or "oocyte incubation" or "IVM"or "priming"

AND

Keywords CONTAINS "HCG" or "human chorionic gonadotrophin" or "human chorionic gonadotropin" or"chorionic gonadotrophins"or "urinary HCG"or "uHCG" or "u-HCG "or "recombinant HCG" or"rhCG"or "r-HCG" or Title CONTAINS "HCG" or "human chorionic gonadotrophin" or "human chorionic gonadotropin" or"chorionic gonadotrophins" or"urinary HCG"or "uHCG" or "u-HCG "or "recombinant HCG" or"rhCG" or "r-HCG" (122 hits)

\section{CENTRAL (CRSO web platform)}


from inception until 29 August 2016

$\# 1\left(\left(\right.\right.$ in vitro adj3 matur $\left.\left.{ }^{\star}\right)\right): \mathrm{TI}, \mathrm{AB}, \mathrm{KY}(90)$

\#2IVM*:TI,AB,KY142

\#3MESH DESCRIPTOR In Vitro Oocyte Maturation Techniques EXPLODE ALL TREES (8)

\#4((in vivo adj3 matur $\left.\left.{ }^{*}\right)\right): T I, A B, K Y(11)$

\#5((oocyte* adj3 priming)):TI,AB,KY (2)

\#6((oocyte* adj3 maturation)):TI,AB,KY (264)

$\# 7\left(\left(\right.\right.$ oocyte $^{*}$ adj3 activat $\left.\left.^{\star}\right)\right): \mathrm{TI}, \mathrm{AB}, \mathrm{KY}(23)$

\#8\#1 OR \#2 OR \#3 OR \#4 OR \#5 OR \#6 OR \#7 (447)

\#9MESH DESCRIPTOR Chorionic Gonadotropin EXPLODE ALL TREES (663)

\#10(Human chorionic gonadotropin):TI,AB,KY5 (42)

\#11(Human chorionic gonadotrophin):TI,AB,KY (298)

\#12HCG:TI,AB,KY (1441)

\#13uHCG:TI,AB,KY (11)

\#14recHCG:TI,AB,KY (2)

\#15rHCG:TI,AB,KY (41)

\#16\#9 OR \#10 OR \#11 OR \#12 OR \#13 OR \#14 OR \#15 (1835)

\#17\#8 AND \#16 (149)

\section{MEDLINE (Ovid platform)}

from 1946 until 29 August 2016

1 (in vitro adj3 matur\$).tw. (7661)

2 ivm\$.tw. (2773)

3 (in vivo adj3 matur\$).tw. (2047)

4 (invivo adj3 matur\$).tw. (0)

5 (invitro adj3 matur\$).tw. (1)

6 (oocyte\$ adj3 maturation).tw. (7475)

7 (oocyte\$ adj3 activat\$).tw. (2250)

8 (oocyte\$ adj3 priming).tw. (33)

9 or/1-8 (16973)

10 Human chorionic gonadotropin.tw. (12465)

11 Human chorionic gonadotrophin.tw. (3925)

12 HCG.tw. (22591)

13 exp chorionic gonadotropin/ or exp chorionic gonadotropin, beta subunit, human/ (30373)

14 uHCG.tw. (19)

15 recHCG.tw. (2)

16 rHCG.tw. (178)

17 or/10-16 (41010)

189 and 17 (1155)

19 randomized controlled trial.pt. (429099)

20 controlled clinical trial.pt. (91610)

21 randomized.ab. (368090)

22 placebo.tw. (183053)

23 clinical trials as topic.sh. (179120)

24 randomly.ab. (262214)

25 trial.ti. (160998)

26 (crossover or cross-over or cross over).tw. (70931)

27 or/19-26 (1087608)

28 (animals not (humans and animals)).sh. (4271460)

2927 not 28 (1001632)

3029 and 18 (117)

\section{Embase (Ovid platform)}

from 1974 until 29 August 2016

1 (in vitro adj3 matur\$).tw. (8933)

2 ivm\$.tw. (3876)

3 (in vivo adj3 matur\$).tw. (2307)

4 (invitro adj3 matur\$).tw. (40) 
5 (invivo adj3 matur\$).tw. (13)

6 (oocyte\$ adj3 maturation).tw. (8758)

7 (oocyte\$ adj3 activat\$).tw. (2564)

8 (oocyte\$ adj3 priming).tw. (39)

9 or/1-8 (20013)

10 Human chorionic gonadotropin.tw. (12878)

11 Human chorionic gonadotrophin.tw. (4031)

12 HCG.tw. (27137)

13 exp chorionic gonadotropin/ (41392)

14 uHCG.tw. (36)

15 recHCG.tw. (8)

16 rHCG.tw. (311)

17 or/10-16 (52714)

18 Clinical Trial/ (863317)

19 Randomized Controlled Trial/ (414767)

20 exp randomization/ (71725)

21 Single Blind Procedure/ (22860)

22 Double Blind Procedure/ (131054)

23 Crossover Procedure/ (48406)

24 Placebo/ (279931)

25 Randomi?ed controlled trial\$.tw. (142411)

26 Rct.tw. (21315)

27 random allocation.tw. (1555)

28 randomly allocated.tw. (25478)

29 allocated randomly.tw. (2151)

30 (allocated adj2 random).tw. (762)

31 Single blind\$.tw. (17882)

32 Double blind\$.tw. (165051)

33 ((treble or triple) adj blind\$).tw. (582)

34 placebo\$.tw. (237914)

35 prospective study/ (348637)

36 or/18-35 (1609572)

37 case study/ (39749)

38 case report.tw. (312827)

39 abstract report/ or letter/ (971282)

40 or/37-39 (1316619)

4136 not 40 (1567967)

4241 and 9 and 17 (251)

\section{PsycINFO (Ovid platform)}

from 1806 until 29 August 2016

1 in vitro maturation.tw. (12)

2 ivm.tw. (39)

3 in vivo maturation.tw. (1)

4 or/1-3 (47)

5 Human chorionic gonadotropin.tw. (87)

6 Human chorionic gonadotrophin.tw. (10)

7 HCG.tw. (87)

8 exp Gonadotropic Hormones/ (3979)

9 or/5-7 (129)

104 and $9(2)$

\section{CINAHL (EBSCO platform)}

from 1982 until 29 August 2016

$\begin{array}{lll}\text { \# } & \text { Query } & \text { Results }\end{array}$


(Continued)

\begin{tabular}{|c|c|c|}
\hline S28 & S15 AND S27 & 13 \\
\hline S27 & $\begin{array}{l}\text { S16 OR S } 17 \text { OR S18 OR S19 OR S } 20 \text { OR S } 21 \text { OR S } 22 \text { OR S23 OR S24 OR S } 25 \text { OR } \\
\text { S26 }\end{array}$ & 954,451 \\
\hline S26 & TX allocat* ${ }^{\star}$ andom ${ }^{\star}$ & 4,243 \\
\hline S25 & (MH "Quantitative Studies") & 13,282 \\
\hline S24 & (MH "Placebos") & 9,173 \\
\hline S23 & TX placebo* & 33,620 \\
\hline S22 & TX random* allocat* & 4,243 \\
\hline S20 & TX randomi $^{\star}$ control $^{\star}$ trial $^{\star}$ & 85,907 \\
\hline S19 & 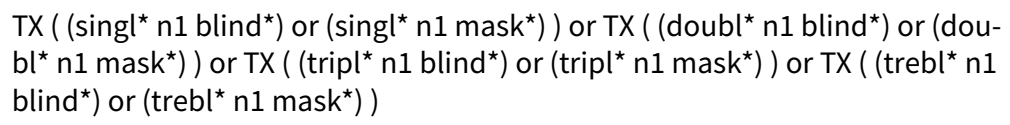 & 763,614 \\
\hline S18 & TX clinic ${ }^{\star}$ n1 trial* & 170,899 \\
\hline S17 & PT Clinical trial & 77,668 \\
\hline S16 & (MH "Clinical Trials+") & 186,062 \\
\hline S14 & S8 OR S9 OR S10 OR S11 OR S12 OR S13 & 1,216 \\
\hline S13 & $\mathrm{TX}$ rHCG & 6 \\
\hline $\mathrm{S} 12$ & TX uHCG & 1 \\
\hline S11 & TX HCG & 740 \\
\hline S10 & TX Human chorionic gonadotropin & 578 \\
\hline S9 & TX Human chorionic gonadotrophin & 170 \\
\hline S8 & (MM "Gonadotropins, Chorionic") & 498 \\
\hline S7 & S1 OR S2 OR S3 OR S4 OR S5 OR S6 & 175 \\
\hline S6 & TX (oocyte* N3 prim) & 7 \\
\hline S5 & TX (oocyte* N3 activat $^{\star}$ ) & 11 \\
\hline S4 & TX (oocyte* N3 maturation) & 64 \\
\hline S3 & TX (in vivo N3 matur ${ }^{\star}$ ) & 26 \\
\hline S2 & TXIVM & 38 \\
\hline
\end{tabular}


(Continued)

\section{7. 'ClinicalTrials.gov', a service of the US national Institute of Health <13 February 2016>}

From inception to 29 August 2016

Search strategy:

1. In Vitro Maturation AND Human Chorionic Gonadotrophin (45)

2. In Vitro Maturation AND HCG (58)

3. IVM AND Human Chorionic Gonadotrophin (1)

4. IVM AND HCG (2)

8. WHO International Clinical Trials Registry Platform (ICTRP) <13 February 2016>

From inception to 29 August 2016

Search strategy:

1. In Vitro Maturation AND Human Chorionic Gonadotrophin (0)

2. In Vitro Maturation AND HCG (3)

9. Searches for papers recently published but not yet indexed in the major databases:

\section{Search engine: PubMed <13 February 2015 to 15 August 2016>}

From inception to 29 August 2016

Search strategy:

(In Vitro Maturation OR IVM) AND (Human chorionic gonadotrophin OR HCG) (62)

Search engine: Google Scholar <13 February 2015 to 15 August 2016>

From inception to 29 August 2016

Search strategy:

(In Vitro Maturation OR IVM) AND (Human chorionic gonadotrophin OR HCG) (36)

\section{Searches for reviews as a potential source of references}

From inception to 29 August 2016

Search engine: PubMed, a 'Systematic Review' search under "Article Type - Review' link <13 April 2016>

From inception to 29 August 2016

Search strategy:

(In Vitro Maturation OR IVM) AND (Human chorionic gonadotrophin OR HCG) (4)

\section{Appendix 2. Inclusion Criteria}

Date

Data extractor 
(Continued)

Trial authors

\section{Year of Publication}

Journal

\section{1) Design}

Described as randomised controlled trial?

Yes

No

Unclear

If 'no' then exclude. If 'yes' then go to question 2.

\section{2) Participants}

a) women undergoing IVM for subfertility

Unclear

If 'no' exclude, otherwise go to question 3.

\section{3) Interventions}

a) hCG compared to placebo priming Yes

No

Unclear

b) hCG compared to no priming

Yes

No

Unclear

c) different doses of hCG compared Yes

No

Unclear

d) different timings of hCG compared Yes

No

Unclear

If 'no' to all a to d) then exclude, otherwise go to final decision.

\section{Final Decision}

Include if 'yes' to all of Q1 and 2 and any of Q3.

Exclude if 'no' to any of Q1 or 2 or all of Q3. 
Excluded or unclear because:

If 'unclear', action taken:

\section{Appendix 3. Data Extraction Form}

\section{Characteristics of trial}
1. Concealment of allocation:
i) third party (telephone)
ii) trialist (computer, sealed envelope, register)

\section{Randomisation: \\ i) computer-generated \\ ii) random number table}
3. Study design:
i) blinding
ii) baseline comparability of groups
iii) withdrawals
iv) duration of follow-up
v) type of follow-up
4. Study size:
i) number recruited
ii) number randomised
iii) number excluded
iv) number analysed
v) losses to follow-up
5. Setting:
i) multi-/single-centre
ii) location
iii) duration
6. Interventions:
i) hCG or placebo priming
ii) hCG or no priming 
(Continued)
iii) different doses of hCG
iv) different timings of hCG
7. Analysis:
i) a priori power calculation
ii) intention-to-treat analysis
iii) standardisation of outcome measures
iv) losses to follow-up
v) publication bias
vi) methodological heterogeneity
vii) statistical heterogeneity

8. Completeness of follow-up until the determination of primary outcome measures

\section{Appendix 4. Assessment of Risk of Bias in Included Studies}

\section{See Higgins 2011 for assessment criteria}

\section{Date}

Trial authors

\section{Year of Publication}

\section{Journal}

\section{Sequence Generation:}

was the allocation sequence adequately generated?

\section{Allocation concealment:}

was the allocation adequately concealed?

\section{Blinding:}

was allocation of interventions adequately concealed?

4. Incomplete outcome data:

were incomplete outcome data adequately addressed?

\section{Selective outcome reporting:}

are the reports of the study free of suggestion of selective outcome reporting? 


\section{HISTORY}

Protocol first published: Issue 9, 2010

Review first published: Issue 11, 2016

\begin{tabular}{lll}
\hline Date & Event & Description \\
\hline 19 December 2007 & $\begin{array}{l}\text { New citation required and major } \\
\text { changes }\end{array}$ & Substantive amendment \\
\hline
\end{tabular}

\section{CONTRIBUTIONS OF AUTHORS}

IG and KV wrote the initial version of the protocol. TC reviewed the protocol.

JR and IG screened the search results and appraised the quality of the studies along with KV. JR extracted and analysed data with discussion and the assistance of IG.

\section{DECLARATIONS OF INTEREST}

TC is the Medical Director of Oxford Fertility, which offers IVM treatment. He has received travel costs and honoraria from Merck Serono and Ferring for giving lectures. Merck Serono are manufacturers of the human chorionic gonadotropin product Profasi used in three included studies. IG works at Oxford Fertility. KV has received research funding from Pfizer Pharmaceuticals and Bayer Healthcare, and honoraria and consultancy fees from Bayer Healthcare and Grunenthal Gmb. JR has no interests to declare.

\section{SOURCES OF SUPPORT}

\section{Internal sources}

- None, Other.

\section{External sources}

- None, Other.

\section{DIFFERENCES BETWEEN PROTOCOLANDREVIEW}

In our protocol, we had planned to also report on biochemical pregnancy rates. However, this outcome was removed as we were also reporting on clinical pregnancy rate, which is more clinically relevant.

We also stated the primary outcome as 'per woman randomised' in the review, rather than 'per woman started', as defined in the protocol. This was to exclude data from studies that randomised women to more than one treatment, or to multiple cycles. We also decided to report miscarriage rate as a primary outcome, rather than secondary, as this would better fulfil our objective of assessing effectiveness and safety of the intervention of hCG priming. Our protocol stated that we would express binary outcomes as Peto odds ratios, however, we changed this to the Mantel-Haenszel method, which has better statistical properties in most situations.

We performed one additional subgroup analysis, stratifying data by PCOS status. This was suggested by peer reviewers in order to improve clinical relevance. The other planned subgroup analyses of patient age and previous failed cycles were also changed to have more specific criteria.

Following peer review, we performed an additional sensitivity analysis for miscarriage rate, and analysed the data per pregnancy.

\section{INDEX TERMS}

\section{Medical Subject Headings (MeSH)}

*In Vitro Oocyte Maturation Techniques; *Infertility, Female; *Pregnancy Rate; Abortion, Spontaneous [epidemiology]; Chorionic Gonadotropin [ ${ }^{\star}$ administration \& dosage] [adverse effects]; Live Birth [epidemiology]; Oocyte Retrieval; Randomized Controlled Trials as Topic; Reproductive Control Agents [*administration \& dosage] [adverse effects]

\section{MeSH check words}

Adult; Female; Humans; Pregnancy 